Check for updates

Cite this: RSC Adv., 2017, 7, 48569

Received 4th August 2017

Accepted 8th October 2017

DOI: $10.1039 / c 7 r a 08633 d$

rsc.li/rsc-advances

\section{Targeted synthesis of cadmium(II) Schiff base complexes towards corrosion inhibition on mild steel $\dagger$}

\author{
Mriganka Das, $\hbar^{\mathrm{a}}$ Amrita Biswas, $\hbar^{\mathrm{b}}$ Bidyut Kumar Kundu, ${ }^{\mathrm{a}}$ Shaikh M. Mobin, (D) ${ }^{a}$ \\ G. Udayabhanu ${ }^{\text {b }}$ and Suman Mukhopadhyay (iD *a
}

Three ligands $\mathrm{L}^{1}\left[N, N\right.$-dimethyl- $N^{\prime}$ - (1-pyridin-2-yl-ethylidene)-ethane-1,2-diamine], $\mathrm{L}^{2}$ [2-morpholino- $N$ (1-(pyridin-2-yl)ethylidene)ethanamine] and $\mathrm{L}^{3}$ [(2-(piperidin-1-yl)- $N$-(1-(pyridin-2-yl)ethylidene)ethanamine)] were introduced to prepare five $\mathrm{Cd}(॥)$ Schiff base complexes $\left[\mathrm{Cd}\left(\mathrm{L}^{1}\right)_{2}\right]\left(\mathrm{ClO}_{4}\right)_{2}(1)$, [Cd( $\left.\left.\mathrm{L}^{1}\right)(\mathrm{Cyanoacetate})(\mathrm{OAc})\right]$ (2), $\left[\mathrm{Cd}_{2}\left(\mathrm{~L}^{1}\right)_{2}\left(\mathrm{~N}_{3}\right)_{4}\right]$ (3), $\left[\mathrm{Cd}\left(\mathrm{L}^{2}\right)\left(\mathrm{N}_{3}\right)_{2}\right]_{n}(4),\left[\mathrm{Cd}_{2}\left(\mathrm{~L}^{3}\right)_{2}\left(\mathrm{~N}_{3}\right)_{4}\right]_{n}(5)$ and the corrosion inhibition properties of these complexes on mild steel upon treatment with $15 \% \mathrm{HCl}$ have been examined where azide complexes have shown corrosion inhibition properties as revealed by electrochemical impedance spectroscopy and potentiodynamic polarization. Field emission scanning electron microscopy (FE-SEM) images show that the mild steel surface was protected by cadmium complexes. Among azido complexes polymeric complexes have higher inhibition activity which was further explained using density functional theory. So finally a new bridge between nuclearity driven coordination inorganic chemistry and materials as well as corrosion engineering was established by this observation.

\section{Introduction}

Inhibitors are generally used to minimize the metal loss from corrosive environments. Metal finds wide application in several industries, such as chemical and petrochemical industries. ${ }^{\mathbf{1 2}}$ In oil industries, corrosion is a major problem and it is controlled by using different kinds of inhibitors. Several techniques (pipe line cleaning, acid pickling, etc.) are used in industries where utilization of acids make metals highly susceptible to corrosion. ${ }^{3-5}$ Inhibitors are widely used to minimize the metal loss during such processes. ${ }^{6}$ Corrosion inhibition is a surface phenomenon where the adsorption of the organic and inorganic compounds on the metal surface serves as a means of achieving the aim. ${ }^{7}$ There are various types of organic and inorganic compounds which have been studied as inhibitors for protecting metals against corrosion. In this scenario, Schiff bases are studied extensively due to the presence of $>\mathrm{C}=\mathrm{N}-$ groups which allow the corresponding Schiff bases to get adsorbed on the surface of mild steel and to form a monolayer

${ }^{a}$ Department of Chemistry, School of Basic Sciences, Indian Institute of Technology Indore, Khandwa Road, Simrol, Indore 453552, India. E-mail: suman@iiti.ac.in; Fax: +917312361 482; Tel: +917312438735

${ }^{b}$ Department of Applied Chemistry, Indian School of Mines, Dhanbad, Jharkhand, India

$\dagger$ Electronic supplementary information (ESI) available. CCDC 958288, 958289, 958287, 1498769 and 1498770 contain the supplementary crystallographic data for 1, 2, 3, 4 and 5 respectively. For ESI and crystallographic data in CIF or other electronic format see DOI: $10.1039 / \mathrm{c} 7 \mathrm{ra08633} \mathrm{d}$

\$ These authors contributed equally. on the surface spontaneously. Therefore, it can act as an effective corrosion inhibitor ${ }^{\mathbf{8}, \mathbf{9}}$ for mild steel, ${ }^{\mathbf{1 0 - 1 3}}$ stainless steel, ${ }^{\mathbf{1 4 , 1 5}}$ iron, nickel, ${ }^{16}$ copper, ${ }^{17}$ aluminum, ${ }^{18}$ and alloy, ${ }^{19}$ in various aggressive solutions. The Schiff base ligands form stable complexes closely packed in the coordination sphere of metal ion to generate another class of compounds for corrosion inhibition. ${ }^{20-22}$ The inhibitors work on the metal surface through the adsorption mechanism. The adsorption of an organic compound depends on the number of functional groups taking part. The interaction of inhibitor molecules with the metal surface is influenced by several factors, such as electron charge density, molecular size, geometry and number of hetero atoms, such as $\mathrm{N}, \mathrm{O}, \mathrm{S}$ present in the molecule. ${ }^{23}$

In industry, cadmium plating offers an exceptional bonding on the surface and is being increasingly used in aircraft manufacturing and is a preferred coating for the salt water environment. Recently, Schiff bases are getting more attention in the field of corrosion inhibition of mild steel. ${ }^{24-26}$ With this point of view researchers have been focusing on metal coordination complexes to quantify their corrosion inhibition property. ${ }^{10,27,28}$ Apart from this the role of sodium azide as a corrosion inhibitor is also well described in literature. ${ }^{29}$ However, to the best of our knowledge, there is only one report where mild steel corrosion inhibition using cadmium coordination complexes have been explored. ${ }^{30}$ Although cadmium has toxic effects on biological systems but as mentioned earlier that cadmium based system can effectively inhibit corrosion on mild steel, therefore we have selected this metal ion to explore the effectiveness of the cadmium based coordination complexes 
and understand the underlying mechanism so that it can help to develop more fruitful inhibitory systems in future. Furthermore, although toxic, effective inhibitor may get utilized in closed systems with proper recovery of the toxic metal ion. Taking account of all these facts, herein we have synthesized and characterized five cadmium Schiff base complexes and explored their corrosion inhibition property on mild steel in $15 \% \mathrm{HCl}$ solution. Most of the complexes show considerable corrosion inhibition property while one polymeric cadmium azide complex has shown the maximum inhibition efficiency, which is quite good in comparison with other metal complex reported earlier. ${ }^{\mathbf{1 0 , 1 1 , 1 3 , 2 0 , 2 7 , 3 1}}$ The corrosion inhibition efficiency was studied by electrochemical methods and protection of metal surface by Cd(II) complexes was shown by FE-SEM images. Nuclearity driven corrosion inhibition trend of Cd(II) complexes was further corroborated by quantum chemical calculations.

\section{Experimental section}

\subsection{Materials and methods}

All the chemical reagents required were purchased from Sigma, except $\mathrm{HCl}$ (purchased from Ranbaxy Fine Chemicals) and used without further purification. Infrared spectra $\left(4000-500 \mathrm{~cm}^{-1}\right)$ were recorded with a BRUKER TENSOR 27 instrument in $\mathrm{KBr}$ pellets. Nuclear Magnetic Resonance (NMR) spectra were recorded in AVANCE III 400 Ascend Bruker BioSpin machine at ambient temperature. Mass spectrometric analyses were done on Bruker-Daltonics, micro TOF-Q II mass spectrometer and elemental analyses were carried out with a Thermo Flash 2000 elemental analyzer.

\subsection{X-ray crystallography}

Single crystal X-ray structural studies of 1-5 were performed on a CCD Agilent Technologies (Oxford Diffraction) SUPER NOVA diffractometer. Data for all the complexes were collected at 150(2) K except complex 4 which was taken 298(2) K using graphite-monochromated Mo $\mathrm{K} \alpha$ radiation $\left(\lambda_{\alpha}=0.71073 \AA\right)$. The strategy for the data collection was evaluated by using the CrysAlisPro CCD software. The data were collected by the standard 'phi-omega scan techniques and were scaled and reduced using CrysAlisPro RED software. The structures were solved by direct methods using SHELXS-97 and refined by full matrix least-squares with SHELXL-97, refining on $\mathrm{F}^{2} \cdot{ }^{32}$ The positions of all the atoms were obtained by direct methods. All non-hydrogen atoms were refined anisotropically. The remaining hydrogen atoms were placed in geometrically constrained positions and refined with isotropic temperature factors, generally $1.2 U_{\text {eq }}$ of their parent atoms. The crystal and refinement data are summarized in Table 1.

\subsection{Synthesis of Schiff base ligands $\left(L^{1}, L^{2}\right.$ and $\left.L^{3}\right)$}

Three ligands $\mathbf{L}^{\mathbf{1}}\left[N, N\right.$-dimethyl- $N^{\prime}$-(1-pyridin-2-yl-ethylidene)-ethane1,2-diamine], $\quad \mathbf{L}^{\mathbf{2}} \quad$ [2-morpholino- $N$-(1-(pyridin-2-yl)ethylidene) ethanamine $]$ and $\mathbf{L}^{3}$ [(2-(piperidin-1-yl)- $N$-(1-(pyridin-2-yl)ethylidene) ethanamine)] were prepared following the procedure reported in literature. ${ }^{33,34}$ These were used for preparation of metal complexes without further purification.

\subsection{Synthesis of $\left[\mathrm{Cd}\left(\mathrm{L}^{1}\right)_{2}\right]\left(\mathrm{ClO}_{4}\right)_{2}(1)$}

$0.19 \mathrm{~g}$ ( $1 \mathrm{mmol})$ of Schiff base ligand $\mathbf{L}^{\mathbf{1}}$ dissolved in $10 \mathrm{~mL}$ of methanol was added drop wise into a solution of $0.15 \mathrm{~g}$ of $\mathrm{Cd}\left(\mathrm{ClO}_{4}\right)_{2}(0.5 \mathrm{mmol})$ in $5 \mathrm{~mL}$ of methanol. The mixture was stirred for 1 hour at room temperature and filtered thereafter. Colourless block-shaped crystals of 1, suitable for X-ray diffraction, were formed after 15 days on slow evaporation of the filtrate in air. Yield: $78 \%$ (based on metal salt). Anal. calcd (\%) $\mathrm{C}_{22} \mathrm{H}_{34} \mathrm{CdCl}_{2} \mathrm{~N}_{6} \mathrm{O}_{8}$ : C, 38.08; $\mathrm{H}, 4.94 ; \mathrm{N}, 12.11$. Found (\%): C, 37.98; H, 4.90; N, 11.77. ${ }^{1} \mathrm{H}$ NMR (400.13 MHz, 298 K, DMSO-d 6 ): $\delta$ 8.43-8.29 (m, 6H, aryl), 7.72 (d, 2H, aryl), 3.95 (br. d, 4H, $\mathrm{CH}_{\text {2alk }}$ ), 2.96 (br. d, 2H, $\mathrm{CH}_{2 \text { alk }}$ ), 2.70 (s, 6H, $\mathrm{CH}_{3 \text { alk }}$ and $2 \mathrm{H}$, $\mathrm{CH}_{\text {2alk }}$ ), 2.17 (s, 12H, N( $\left.\left.\mathrm{CH}_{3}\right)_{2}\right) .{ }^{13} \mathrm{C}$ NMR (100.61 MHz, $293 \mathrm{~K}$, DMSO-d $\left.{ }_{6}\right): \delta 169.7$ ( $\left.\mathrm{C}_{\text {imine }}\right), 149.4\left(\mathrm{C}_{\text {aryl }}\right), 148.1\left(\mathrm{C}_{\text {aryl }}\right), 141.4$ $\left(\mathrm{C}_{\text {aryl }}\right), 128.0\left(\mathrm{C}_{\text {aryl }}\right), 125.3\left(\mathrm{C}_{\text {aryl }}\right), 58.2\left(\mathrm{NCH}_{2}\right), 45.8\left(\mathrm{NCH}_{2}\right), 45.5$ $\left(\mathrm{NCH}_{3}\right), 16.7\left(\mathrm{CH}_{3} \mathrm{C}\right)$. ESI-MS $(\mathrm{m} / z) 248.10\left[\mathrm{Cd}\left(\mathbf{L}^{\mathbf{1}}\right)_{2}\right]^{2+}, 595.16$ $\left[\left(\mathrm{Cd}\left(\mathbf{L}^{\mathbf{1}}\right)_{2}\right) \mathrm{ClO}_{4}\right]^{+}$.

\subsection{Synthesis of $\left[\mathrm{Cd}\left(\mathrm{L}^{1}\right)(\right.$ cyanoacetate $\left.)(\mathrm{OAc})\right](2)$}

Ligand $\mathbf{L}^{1}$ (0.5 mmol, $\left.0.09 \mathrm{~g}\right)$ and $\mathrm{Cd}(\mathrm{OAc})_{2} \cdot 2 \mathrm{H}_{2} \mathrm{O}(0.5 \mathrm{mmol}$, $0.13 \mathrm{~g}$ ) were stirred in methanol $(15 \mathrm{~mL})$ for $30 \mathrm{~min}$ at room temperature. A methanolic solution $(10 \mathrm{~mL})$ of piperadinium salt of cyano acetic acid ( $1 \mathrm{mmol}, 0.17 \mathrm{~g}$ ) was added into it thereafter and stirring was continued for 1 hour. Then it was concentrated and filtered. The colourless block-shaped crystals of 2, suitable for X-ray diffraction, were formed after 6 days on slow evaporation of the filtrate in air. Yield: $72 \%$ (based on metal salt). Anal. calcd (\%) $\mathrm{C}_{16} \mathrm{H}_{22} \mathrm{CdN}_{4} \mathrm{O}_{4}$ : C, 43.01; $\mathrm{H}, 4.96 ; \mathrm{N}$, 12.54. Found (\%): C, 42.80; H, 5.04; N, 12.00. ${ }^{1} \mathrm{H}$ NMR (400.13 MHz, $298 \mathrm{~K}, \mathrm{DMSO}_{\mathrm{d}}$ ): $\delta 8.70(\mathrm{~d}, J=4 \mathrm{~Hz}, 1 \mathrm{H}, \operatorname{aryl}), 8.21(\mathrm{~m}, 2 \mathrm{H}$, aryl), 7.77 (m, 1H, aryl), $3.70\left(\mathrm{~s}, 3 \mathrm{H}, \mathrm{CH}_{3}\right.$ (acetate)), 2.73-2.50 $\left(6 \mathrm{H}, \mathrm{CH}_{\text {2alk }}\right), 2.33$ (s, 6H, N( $\left.\left.\mathrm{CH}_{3}\right)_{2}\right), 1.79\left(\mathrm{~s}, 3 \mathrm{H}, \mathrm{CH}_{3 \mathrm{alk}}\right) .{ }^{13} \mathrm{C} \mathrm{NMR}$ $\left(100.61 \mathrm{MHz}, 293 \mathrm{~K}, \mathrm{DMSO}-\mathrm{d}_{6}\right): \delta 177.0$ ( $\left.\mathrm{C}_{\text {cyano-acetate }}\right), 167.1$ ( $\left.\mathrm{C}_{\text {acetate }}\right), 165.9$ ( $\left.\mathrm{C}_{\text {imine }}\right), 149.5\left(\mathrm{C}_{\text {aryl }}\right), 148.1\left(\mathrm{C}_{\text {aryl }}\right), 140.1\left(\mathrm{C}_{\text {aryl }}\right)$, $127.2\left(\mathrm{C}_{\text {aryl }}\right), 124.0\left(\mathrm{C}_{\text {aryl }}\right), 117.8$ ( $\left.\mathrm{C}_{\text {cyanide }}\right), 57.2\left(\mathrm{NCH}_{2}\right), 45.5$ $\left(\mathrm{NCH}_{2}\right), 44.9\left(\mathrm{CH}_{2} \mathrm{CN}\right), 25.5\left(\mathrm{CH}_{3} \mathrm{C}\right), 21.8\left(\mathrm{CH}_{3} \mathrm{C}\right), 15.7\left(\mathrm{CH}_{3} \mathrm{C}\right)$. ESI-MS $(m / z) 471.16\left[\mathrm{Cd}\left(\mathbf{L}^{\mathbf{1}}\right)(\right.$ cyanoacetate $\left.)(\mathrm{OAc})\right]+\mathrm{Na}^{+}$.

\subsection{Synthesis of $\left[\mathrm{Cd}_{2}\left(\mathrm{~L}^{1}\right)_{2}\left(\mathrm{~N}_{3}\right)_{4}\right](3)$}

Ligand $\mathbf{L}^{\mathbf{1}}$ (0.5 mmol, $\left.0.09 \mathrm{~g}\right)$ and $\mathrm{Cd}(\mathrm{OAc})_{2} \cdot 2 \mathrm{H}_{2} \mathrm{O}(0.5 \mathrm{mmol}$, $0.13 \mathrm{~g})$ were taken in methanol $(15 \mathrm{~mL})$ and stirred for $30 \mathrm{~min}$ at room temperature. After that an aqueous solution $(10 \mathrm{~mL})$ of sodium azide ( $1 \mathrm{mmol}, 0.06 \mathrm{~g}$ ) was added drop wise into it with continuous stirring. The stirring was continued for 1 hour. Then the solvent was evaporated to concentrate the solution and it was filtered. Finally the colourless block-shaped crystals of 3, suitable for X-ray diffraction, were formed after 4 days on slow evaporation of the filtrate in air. Yield: $82 \%$ (based on metal salt). Anal. calcd (\%) $\mathrm{C}_{22} \mathrm{H}_{34} \mathrm{Cd}_{2} \mathrm{~N}_{18}$ : C, 34.08; $\mathrm{H}, 4.42 ; \mathrm{N}$, 32.51. Found (\%): C, 33.31; H, 4.28; N, 31.70. ${ }^{1} \mathrm{H}$ NMR (400.13 MHz, $\left.298 \mathrm{~K}, \mathrm{DMSO}_{6}\right): \delta 8.38(\mathrm{~d}, J=4 \mathrm{~Hz}, 2 \mathrm{H}$, aryl), $8.08(\mathrm{~m}, 4 \mathrm{H}$, aryl), $7.69\left(\mathrm{~d}, 2 \mathrm{H}\right.$, aryl), 3.54-3.42 (t, $\left.J=12 \mathrm{~Hz}, 8 \mathrm{H}, \mathrm{CH}_{2 \mathrm{alk}}\right), 2.36$ (s, 6H, $\mathrm{CH}_{3 \text { alk }}$ ), 2.17 (s, 12H, N( $\left.\left.\mathrm{CH}_{3}\right)_{2}\right) .{ }^{13} \mathrm{C} \mathrm{NMR}(100.61 \mathrm{MHz}$, 
Table 1 Crystallographic data and structure refinement parameters for 1, 2, 3, 4 and 5

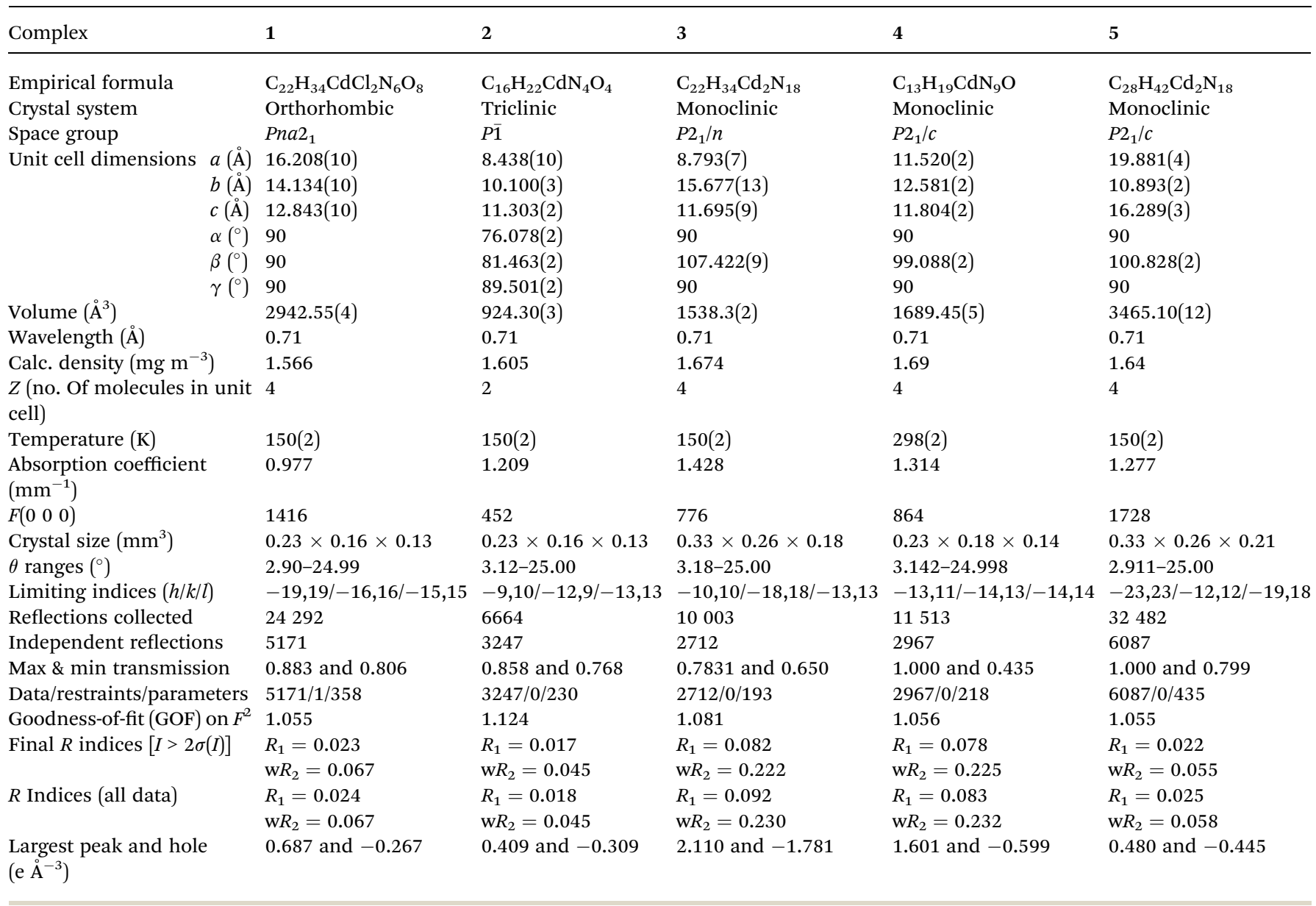

$\left.293 \mathrm{~K}, \mathrm{DMSO}-\mathrm{d}_{6}\right): \delta 169.1\left(\mathrm{C}_{\text {imine }}\right), 148.8\left(\mathrm{C}_{\text {aryl }}\right), 147.5\left(\mathrm{C}_{\text {aryl }}\right)$, 141.3 ( $\left.\mathrm{C}_{\text {aryl }}\right), 128.2\left(\mathrm{C}_{\text {aryl }}\right), 124.6\left(\mathrm{C}_{\text {aryl }}\right), 79.3\left(\mathrm{NCH}_{2}\right), 56.8\left(\mathrm{NCH}_{2}\right)$, $44.4\left(\mathrm{NCH}_{3}\right), 16.1\left(\mathrm{CH}_{3} \mathrm{C}\right)$. ESI-MS $(\mathrm{m} / z) 347.07\left[\mathrm{Cd}_{2}\left(\mathbf{L}^{\mathbf{1}}\right)_{2}\left(\mathrm{~N}_{3}\right)_{2}\right]^{2+}$, $734.15\left[\mathrm{Cd}_{2}\left(\mathbf{L}^{\mathbf{1}}\right)_{2}\left(\mathrm{~N}_{3}\right)_{3}\right]^{+}$.

\subsection{Synthesis of $\left[\operatorname{Cd}\left(L^{2}\right)\left(N_{3}\right)_{2}\right]_{n}(4)$}

$0.11 \mathrm{~g}$ of ligand $\mathrm{L}^{2}(0.5 \mathrm{mmol})$ and $0.13 \mathrm{~g}$ of $\mathrm{Cd}(\mathrm{OAc})_{2} \cdot 2 \mathrm{H}_{2} \mathrm{O}(0.5$ $\mathrm{mmol}$ ) were mixed in methanol $(15 \mathrm{~mL})$ and stirred for $30 \mathrm{~min}$ at room temperature. Then $10 \mathrm{~mL}$ aqueous sodium azide ( $1 \mathrm{mmol}, 0.06 \mathrm{~g}$ ) was added into it slowly. The solution was stirred for 1 hour more. After that the solvent was evaporated to make it concentrate and then it was filtered. Finally the colourless block-shaped crystals of $\mathbf{4}$, suitable for X-ray diffraction, were formed after 6 days on slow evaporation of the filtrate in air. Yield: $76 \%$ (based on metal salt). Anal. calcd (\%) $\mathrm{C}_{13} \mathrm{H}_{19} \mathrm{CdN}_{9} \mathrm{O}$ : C, 36.33; H, 4.46; N, 29.33. Found (\%): C, 37.10; $\mathrm{H}, 4.28$; N, 30.70. ${ }^{1} \mathrm{H}$ NMR (DMSO-d $\left.{ }_{6}\right) 8.80(\mathrm{~d}, J=4 \mathrm{~Hz}, 1 \mathrm{H}$, aryl), 8.29-8.24 (m, 2H, aryl), 7.87-7.85 (m, 1H, aryl), 3.80, $3.76(\mathrm{~d}, 4 \mathrm{H}$, $\left.2 \mathrm{CH}_{2}\right), 3.69\left(\mathrm{~s}, 4 \mathrm{H}, 2 \mathrm{CH}_{2}\right), 2.79-2.77\left(\mathrm{t}, 4 \mathrm{H}, \mathrm{NCH}_{2}\right), 2.69(\mathrm{~s}, 3 \mathrm{H}$, $\left.\mathrm{CH}_{3}\right){ }^{13} \mathrm{C}$ NMR (100.61 MHz, $\left.293 \mathrm{~K}, \mathrm{DMSO}_{6}\right): \delta 165.8\left(\mathrm{C}_{\text {imine }}\right)$, $149.2\left(\mathrm{C}_{\text {aryl }}\right), 140.5\left(\mathrm{C}_{\text {aryl }}\right), 132.3\left(\mathrm{C}_{\text {aryl }}\right), 127.6\left(\mathrm{C}_{\text {aryl }}\right), 124.2\left(\mathrm{C}_{\text {aryl }}\right)$, 64.76-57.88 (4C, 2- $\left.\mathrm{CH}_{2 \mathrm{morph}}\right), 53.44-44.36\left(2 \mathrm{C}, 2 \mathrm{CH}_{2}\right), 15.77$ $\left(1 \mathrm{C}, \mathrm{CH}_{3}\right)$

\subsection{Synthesis of $\left[\mathrm{Cd}_{2}\left(\mathrm{~L}^{3}\right)_{2}\left(\mathrm{~N}_{3}\right)_{4}\right]_{n}(5)$}

In $15 \mathrm{~mL}$ of methanol, ligand $\mathbf{L}^{3}(0.5 \mathrm{mmol}, 0.12 \mathrm{~g})$ and $\mathrm{Cd}(\mathrm{OAc})_{2} \cdot 2 \mathrm{H}_{2} \mathrm{O}(0.5 \mathrm{mmol}, 0.13 \mathrm{~g})$ were stirred for $30 \mathrm{~min}$ at room temperature. An aqueous solution $(10 \mathrm{~mL})$ of sodium azide ( $1 \mathrm{mmol}, 0.06 \mathrm{~g}$ ) was added into it thereafter and stirring was continued for 1 hour. The reaction mixture was concentrated and filtered and then colourless block-shaped crystals of $\mathbf{5}$, suitable for X-ray diffraction, were formed after 7 days on slow evaporation of the filtrate in air. Yield: $74 \%$ (based on metal salt). Anal. calcd (\%) $\mathrm{C}_{28} \mathrm{H}_{42} \mathrm{Cd}_{2} \mathrm{~N}_{18}$ : C, 39.31; H, 4.95; N, 29.47. Found (\%): C, 39.81; H, 4.75; N, 30.60. ${ }^{1} \mathrm{H}$ NMR $(400.13 \mathrm{MHz}$, $298 \mathrm{~K}, \mathrm{DMSO}_{\mathrm{d}}$ ): $\delta 8.34(\mathrm{~d}, J=4 \mathrm{~Hz}, 2 \mathrm{H}$, aryl), 8.01 (m, $4 \mathrm{H}$, aryl), 7.62 (d, 2H, aryl), 3.45-3.40 (t, $\left.J=12 \mathrm{~Hz}, 8 \mathrm{H}, \mathrm{CH}_{2 \mathrm{alk}}\right), 2.32(\mathrm{~s}, 6 \mathrm{H}$, $\mathrm{CH}_{3 \text { alk }}$ ), 2.20-2.30 (m, 8H), 1.51-1.52 (m, 8H), 1.17-1.25 (m, 4H). ${ }^{13} \mathrm{C}$ NMR (100.61 MHz, $293 \mathrm{~K}$, DMSO-d ${ }_{6}$ ): $\delta 167.1$ (C $\mathrm{C}_{\text {imine }}$ ), 146.8 $\left(\mathrm{C}_{\text {aryl }}\right), 145.5\left(\mathrm{C}_{\text {aryl }}\right), 140.3\left(\mathrm{C}_{\text {aryl }}\right), 126.2\left(\mathrm{C}_{\text {aryl }}\right), 122.6\left(\mathrm{C}_{\text {aryl }}\right), 45.3$ $\left(\mathrm{NCH}_{2}\right), 35.8\left(\mathrm{NCH}_{2}\right), 24.0-30.0\left(5 \mathrm{C}, 2 \mathrm{CH}_{2}\right), 16.1\left(\mathrm{CH}_{3} \mathrm{C}\right)$.

\subsection{Electrochemical experiments}

The mild steel sheets [composition: $0.055 \% \mathrm{C}, 0.52 \% \mathrm{Mn}$, $0.018 \%$ P, $0.005 \%$ S $0.052 \%$ Si, 0.044\% Al, 0.021\% Cr, 0.006\% $\mathrm{Cu}, 0.001 \% \mathrm{Nb}, 0.001 \% \mathrm{Ti}$ and balance Fe; thickness: $2 \mathrm{~mm}$ ] were collected from Tata Steel, Jamshedpur, India. Square 
shaped $\left(1 \mathrm{~cm}^{2}\right)$ mild steel samples were cut from this and used for the electrochemical experiments. One face of this specimen was sealed using Araldite, after connecting it to a copper wire. This square specimen of mild steel having $1 \mathrm{~cm}^{2}$ exposed area was used as working electrode. In every experiment, metal samples were polished with fine emery paper (grade upto 2000), washed with distilled water, rinsed with acetone, dried and then stored in desiccator prior to their use. All electrochemical experiments were performed in a three-electrode cell, consist of working, reference and the counter electrode. Here saturated calomel electrode and platinum electrode were used as reference and counter electrode respectively. The three electrodes were connected to the Electrochemical Workstation, $\mathrm{CH}$ Instruments model CH660C. All tests were performed in 15\% $\mathrm{HCl}$ medium and unstirred condition at room temperature (298 $\pm 1 \mathrm{~K}$ ) in presence and absence of inhibitor (blank). Prior to polarization, the system was left undisturbed for an hour, which was sufficient to attain stable open circuit potential (OCP).

The potentiodynamic polarization curve was obtained at a scan rate of $1 \mathrm{mV} \mathrm{s}^{-1}$ in the potential range, $+250 \mathrm{mV}$ to $-250 \mathrm{mV}$ with respect to OCP. The corrosion current density $\left(I_{\text {corr }}\right)$ values were obtained by the Tafel extrapolation method using the software provided with the equipment.

Electrochemical Impedence Spectroscopy (EIS) experiments were performed at open circuit potential at applied frequency range $100 \mathrm{kHz}$ to $10 \mathrm{mHz}$ at $298 \pm 1 \mathrm{~K}$ by using AC amplitude signal of $5 \mathrm{mV}$ peak-to-peak.

\subsection{Weight loss measurement}

The clean mild steel coupons were dipped in $400 \mathrm{~mL} \mathrm{15 \%} \mathrm{HCl}$ taken in $500 \mathrm{~mL}$ beaker at $298 \pm 1 \mathrm{~K}$. Mild steel coupons after exposure to corrosive solution were cleaned by washing in running tap water and then by immersing in cleaning solution (solution of $50 \mathrm{~g} \mathrm{SnCl}{ }_{2}$ and $20 \mathrm{~g} \mathrm{Sb} \mathrm{Sb}_{3}$ per liter of conc. $\mathrm{HCl}$ ). The difference of specimen weight before and after the immersion is the corrosion weight loss. The corrosion rate (CR) and percent of inhibition efficiency $\left(\eta_{\mathrm{wt}} \%\right)$ were calculated by following equations

$$
\begin{aligned}
& \mathrm{CR}(\mathrm{mmpy})=\frac{87.6 \times \Delta W}{\mathrm{DAT}} \\
& \eta_{\mathrm{wt}}(\%)=\frac{W^{0}-W}{W^{0}} \times 100
\end{aligned}
$$

where, $\Delta W(\mathrm{mg})$ is the weight loss of mild steel (MS) specimens, $A$ is the total surface area of MS specimen (in $\mathrm{cm}^{2}$ ), $T$ is the immersion time ( $6 \mathrm{~h}), D$ is the density of $\mathrm{MS}\left(\mathrm{g} \mathrm{cm}^{-3}\right), W^{0}$ and $W$ are the weight loss in the absence and presence of inhibitor.

\subsection{Surface analysis}

The surface was characterized by Field Emission Scanning Electronic Microscope (FE-SEM). Micrographs were taken at room temperature $(298 \pm 1 \mathrm{~K})$ after $1 \mathrm{~h}$ and $6 \mathrm{~h}$ immersion of polished metal coupon in $15 \% \mathrm{HCl}$ solution with and without inhibitor.

\subsection{Computational study}

As per representative purpose, we have performed the density functional theory (DFT) calculations for complex $\mathbf{3}$ and complex 4 to understand the nuclearity assisted corrosion inhibition activity. All the calculations are carried out in gaseous phase $\mathrm{e}^{35}$ using RB3LYP level of theory as implemented in the Gaussians 09 package. ${ }^{36}$ The structures of complexes were optimized using LANL2MB basis set for all atoms following the similar protocol reported in earlier literature for cadmium complexes. ${ }^{37}$ The similar trend of calculated results were also obtained when 3$21 \mathrm{G}$ basis set was used for C, N, H, O and LANL2DZ was used for Cd atom. ${ }^{38,39}$ The Fukui functions were calculated using the $\mathrm{Dmol}^{3}$ module. The Fukui function $\left(f_{\mathrm{k}}\right)$ is the first derivative of the electron density $\rho(r)$ with respect to the number of electrons $\mathrm{N}$, in a constant external potential $\nu(r)$ and written as follows. ${ }^{40}$

$$
f_{\mathrm{k}}=\left(\frac{\partial \rho(\vec{r})}{\partial N}\right)_{\nu(\vec{r})}
$$

Finite difference approximations have been used to get Fukui function in favor of nucleophilic and electrophilic attacks as, ${ }^{40}$

$$
\begin{aligned}
& f_{\mathrm{k}}^{+}=q_{\mathrm{k}}(N+1)-q_{\mathrm{k}}(N) \text { [for nucleophilic attack] } \\
& f_{\mathrm{k}}{ }^{-}=q_{\mathrm{k}}(N)-q_{\mathrm{k}}(N-1) \text { [for electrophilic attack] }
\end{aligned}
$$

here, gross charge of the atom $k$ is denoted by $q_{\mathrm{k}}$. The $q_{\mathrm{k}}(N+1)$, $q_{\mathrm{k}}(N)$ and $q_{\mathrm{k}}(N-1)$ are the charges of the anionic, neutral and cationic species, respectively.

\section{Results and discussion}

\subsection{Synthesis}

Ligands $\mathbf{L}^{\mathbf{1}}, \mathbf{L}^{\mathbf{2}}$ and $\mathbf{L}^{\mathbf{3}}$ were prepared by reported methods, respectively. ${ }^{33,34}$ In compound $\mathbf{1}$, ligand to metal ratio was used in $2: 1$ and cadmium perchlorate was used as a metal precursor. In the case of compound 2, piperidinium salt of cyanoacetic acid is used where cyanoacetate ion act as co-ligand (Fig. 1). Compounds 3-5 have been prepared in a methanolic solution of cadmium salt in presence of several ligands $\mathbf{L}^{\mathbf{1}}, \mathbf{L}^{2}$ and $\mathbf{L}^{3}$ and aqueous $\mathrm{NaN}_{3}$ maintaining 1:1:2 ratio (Fig. 1), where azide ion has been utilized as co-ligand.

\subsection{Characterization}

All the compounds were characterized by different spectroscopic techniques apart from elemental analysis. The structures of the compounds were further determined by single crystal Xray crystallography. The IR spectra of compound 1-5 show typical band for stretching vibration of $\mathrm{C}=\mathrm{N}$ in the range of 1590-1600 $\mathrm{cm}^{-1} .^{41}$ This indicates clearly that on complex formation $\mathrm{C}=\mathrm{N}$ stretching frequency shifts in lower frequency region with respect to parent ligand. Compound 1 shows a strong band at $1091 \mathrm{~cm}^{-1}$ assigned to a non-coordinated 


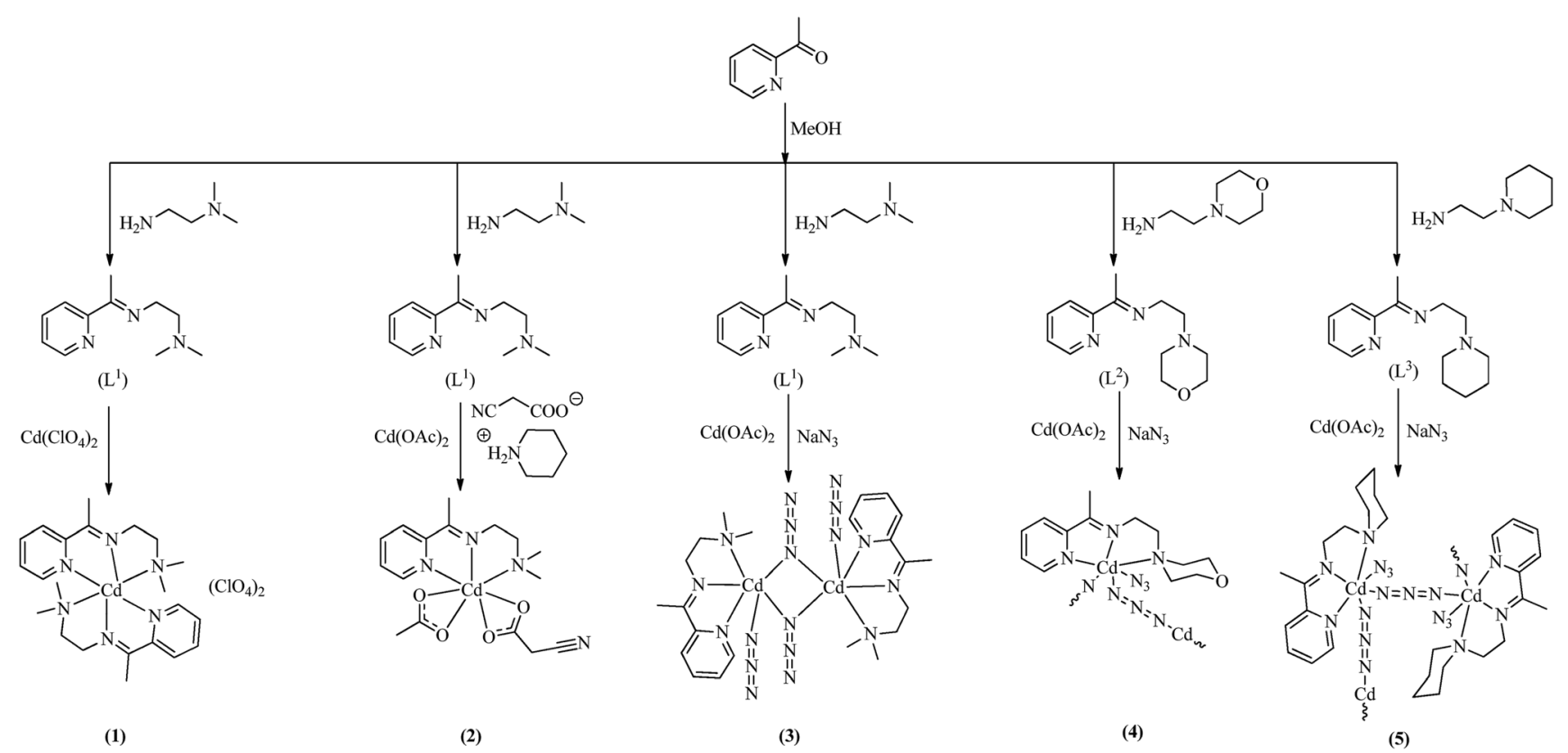

Fig. 1 Synthetic scheme for preparation Cd(॥) complexes.

$\mathrm{ClO}_{4}{ }^{-}$ion. ${ }^{42}$ In the case of complex 2 , a relatively small band is observed at $2255 \mathrm{~cm}^{-1}$ which indicate the presence of nitrile stretching of cyanoacetate. There are two types of bands for azide ligands which have been observed around $2036 \mathrm{~cm}^{-1}$ and $2130 \mathrm{~cm}^{-1}$, respectively for two types of stretching frequency viz., terminal azido and bridging azido in complex 3-5. For metal azido complexes 3-5 the azide ion coordinates to the metal center in different modes. Apart from the conventional terminal connection of azide ion, there are several other bridging modes exist (Fig. $\mathrm{S} 1 \dagger)^{\mathbf{4 3}}$ by which azide ion can get ligated between two metal centers.

Among the above kind of existing bridging modes here we observed mainly the $\mu-1,3$ (end-to-end) and $\mu-1,1$ (doublebridged end-on) bridging coordination modes to generate polynuclear metal complexes. All the coordination bond lengths and bond angles of all complexes around the central cadmium center are tabulated in Table 2 .

\subsection{Crystal structure of complex 1}

Compound 1 crystallized in orthorhombic space group Pna2 $2_{1}$. The cadmium atom is in the distorted octahedral environment and coordinated by two tridentate Schiff base ligands $\left(\mathbf{L}^{\mathbf{1}}\right)$ (Fig. S2 $\dagger$ ). Though there are some coordination angles [N1Cd1-N2 (70.39 $)$; N2-Cd1-N3 $\left(74.06^{\circ}\right)$; N4-Cd1-N5 (73.70 $)$; N5Cd1-N6 $\left(70.57^{\circ}\right)$ ] (Fig. S2 $\dagger$ ) deviating considerably from $90^{\circ}$, however, this can be attributed to the chelating nature of Schiff base ligand. The bond lengths between $\mathrm{Cd}$ atom and $\mathrm{N}$-donor centers are within the range of 2.284(3)-2.448(3) A (Table 2), quite similar to those which have been reported earlier. ${ }^{44}$ The two pyridine rings in the complex cation are approximately perpendicular to each other, making a dihedral angle of $88.57^{\circ}$. The perchlorate anions are linked to the complex cation through $\mathrm{C}-\mathrm{H} \cdots \mathrm{O}$ hydrogen bonds and these hydrogen bonds are mainly responsible for the formation of a supramolecular spiral chain-like structures (Fig. S2 $\dagger$ ). The packing structure discloses that the monomeric units interacted with each other through $\mathrm{C} 21-\mathrm{H} 21 \mathrm{C} \cdots \mathrm{O} 5, \quad \mathrm{C} 4-\mathrm{H} 4 \cdots \mathrm{O} 7$ and $\mathrm{C} 4-\mathrm{H} 4 \cdots \mathrm{O} 6$ hydrogen bonding to make a $1 \mathrm{D}$ chain along $a$ axis. Two such simultaneous 1D chains are further connected through C20H20B $\cdots$ O8, C19-H19A $\cdots$ O6 and C9-H9A $\cdots$ O5 hydrogen bonding to make a $2 \mathrm{D}$ sheet-like structure in $a b$ plane (Fig. $\mathrm{S} 2 \dagger$ ).

\subsection{Crystal structure of complex 2}

Compound $\mathbf{2}$ is a monomeric Cd(II) compound crystalized in the space group $P \overline{1}$. Here central cadmium ion is situated in a seven coordinated geometric environment which is relatively uncommon. ${ }^{45}$ The seven coordination sites of $\mathrm{Cd}(\mathrm{II})$ ion is fulfilled by one tridentate Schiff base ligand $\left(\mathbf{L}^{\mathbf{1}}\right)$, Two O-donor sites of one cyano-acetic acid and two O-donor sites of one acetate (Fig. S3 $\dagger$ ). The bond lengths between $\mathrm{Cd}$ atom and $\mathrm{N}$-donor centers are within the range of 2.23(1)-2.50(2) $\AA$ (Table 2) and Cd-O distances are found to be in the range of 2.30-2.50 A, quite similar to those which have been reported earlier. However, one particular $\mathrm{Cd}(1)-\mathrm{O}(2)$ bond distance was found to be relatively longer ca. 2.73 $\AA$. Each monomeric unit is linked with each other via $\mathrm{C} 13-\mathrm{H} 13 \mathrm{~B} \cdots \mathrm{O} 3, \mathrm{C} 1-\mathrm{H} 1 \cdots \mathrm{O} 1$ and $\mathrm{C} 8-\mathrm{H} 8 \mathrm{~A} \cdots \mathrm{O} 4$ hydrogen bonding (Fig. S3†) to make a 1D chain like structure. Two such simultaneous 1D chains are further connected through C8$\mathrm{H} 8 \mathrm{~B} \cdots \mathrm{N} 4$ hydrogen bonding to make a 2D sheet-like structure (Fig. S3†).

\subsection{Crystal structure of complex 3}

Compound 3 is a symmetric dimeric Cd(II) compound crystalized in the space group $P 2_{1} / n$. Each $\mathrm{Cd}^{2+}$ ion is located in an octahedral geometric environment. The octahedral geometry of 
Table 2 Selected bond lengths $(\AA)$ and bond angles $\left({ }^{\circ}\right)$ of five complexes

\section{Complex 1}

$\mathrm{Cd}(1)-\mathrm{N}(5)$

$\mathrm{Cd}(1)-\mathrm{N}(6)$

$\mathrm{Cd}(1)-\mathrm{N}(3)$

$\mathrm{N}(5)-\mathrm{Cd}(1)-\mathrm{N}(6)$

$\mathrm{N}(1)-\mathrm{Cd}(1)-\mathrm{N}(6)$

$\mathrm{N}(3)-\mathrm{Cd}(1)-\mathrm{N}(6)$

$\mathrm{N}(2)-\mathrm{Cd}(1)-\mathrm{N}(4)$

Complex 2

\section{$\mathrm{Cd}(1)-\mathrm{O}(1)$}

$\mathrm{Cd}(1)-\mathrm{N}(2)$

$\mathrm{Cd}(1)-\mathrm{N}(3)$

$\mathrm{O}(4)-\mathrm{Cd}(1)-\mathrm{N}(2)$

$\mathrm{O}(1)-\mathrm{Cd}(1)-\mathrm{N}(3)$

$\mathrm{N}(2)-\mathrm{Cd}(1)-\mathrm{N}(3)$

Complex 3

$\mathrm{Cd}(1)-\mathrm{N}(1)$

$\mathrm{Cd}(1)-\mathrm{N}(8)$

$\mathrm{Cd}(1)-\mathrm{N}(9)$

$\mathrm{N}(1)-\mathrm{Cd}(1)-\mathrm{N}(4)$

$\mathrm{N}(4)-\mathrm{Cd}(1)-\mathrm{N}(4) \# 1$

$\mathrm{N}(1)-\mathrm{Cd}(1)-\mathrm{N}(9)$

$\mathrm{N}(8)-\mathrm{Cd}(1)-\mathrm{N}(9)$

$\mathrm{N}(7)-\mathrm{Cd}(1)-\mathrm{N}(8)$

Complex 4

$\mathrm{Cd}(1)-\mathrm{N}(7)$

Cd(1)-N(6)\#1

$\mathrm{Cd}(1)-\mathrm{N}(1)$

$\mathrm{N}(2)-\mathrm{Cd}(1)-\mathrm{N}(6) \# 1$

$\mathrm{N}(6) \# 1-\mathrm{Cd}(1)-\mathrm{N}(3)$

$\mathrm{N}(2)-\mathrm{Cd}(1)-\mathrm{N}(4)$

$\mathrm{N}(6) \# 1-\mathrm{Cd}(1)-\mathrm{N}(1)$

$\mathrm{N}(1)-\mathrm{Cd}(1)-\mathrm{N}(4)$

\section{Complex 5}

$\mathrm{Cd}(1)-\mathrm{N}(10)$

$\mathrm{Cd}(1)-\mathrm{N}(2)$

$\mathrm{Cd}(1)-\mathrm{N}(1)$

$\mathrm{Cd}(2)-\mathrm{N}(16)$

$\mathrm{Cd}(2)-\mathrm{N}(6) \# 1$

$\mathrm{Cd}(2)-\mathrm{N}(13)$

$\mathrm{N}(7)-\mathrm{Cd}(1)-\mathrm{N}(10)$

$\mathrm{N}(2)-\mathrm{Cd}(1)-\mathrm{N}(7)$

$\mathrm{N}(3)-\mathrm{Cd}(1)-\mathrm{N}(7)$

$\mathrm{N}(13)-\mathrm{Cd}(2)-\mathrm{N}(14)$
$\mathrm{Cd}(1)-\mathrm{N}(2)$

$\mathrm{Cd}(1)-\mathrm{N}(1)$

$\mathrm{Cd}(1)-\mathrm{N}(4)$

$\mathrm{N}(1)-\mathrm{Cd}(1)-\mathrm{N}(2)$

$\mathrm{N}(2)-\mathrm{Cd}(1)-\mathrm{N}(3)$

$\mathrm{N}(4)-\mathrm{Cd}(1)-\mathrm{N}(5)$

$\mathrm{N}(1)-\mathrm{Cd}(1)-\mathrm{N}(4)$

$96.23(9)$

94.41(9)

2.238(14)

$2.329(17)$

2.431(16)

96.49(6)

98.52(5)

$73.26(6)$

2.231(12)

2.325(8)

$2.380(9)$

91.4(4)

$72.5(4)$

98.3(7)

$73.8(3)$

68.1(3)

2.228(15)

2.391(16)

2.404(15)

87.55(6)

98.20(5)

94.19(5)

89.94(5)

87.74(5)

$\mathrm{Cd}(1)-\mathrm{N}(2)$

$\mathrm{Cd}(1)-\mathrm{N}(4)$

$\mathrm{Cd}(1)-\mathrm{N}(3)$

$\mathrm{N}(4)-\mathrm{Cd}(1)-\mathrm{N}(7)$

$\mathrm{N}(2)-\mathrm{Cd}(1)-\mathrm{N}(3)$

$\mathrm{N}(1)-\mathrm{Cd}(1)-\mathrm{N}(2)$
2.286(2)

2.359(3)

2.448(3)

70.39(9)

74.06(9)

$73.70(10)$

91.58(10)

2.302(15)

$2.344(16)$

2.506(16)

69.46(6)

$85.26(5)$

$89.00(5)$

$\begin{array}{ll}\mathrm{Cd}(1)-\mathrm{N}(4) & 2.299(7) \\ \mathrm{Cd}(1)-\mathrm{N}(4) \# 1 & 2.379(8) \\ \mathrm{Cd}(1)-\mathrm{N}(7) & 2.412(10) \\ \mathrm{N}(1)-\mathrm{Cd}(1)-\mathrm{N}(7) & 91.1(7) \\ \mathrm{N}(8)-\mathrm{Cd}(1)-\mathrm{N}(4) \# 1 & 86.5(3) \\ \mathrm{N}(4)-\mathrm{Cd}(1)-\mathrm{N}(9) & 95.6(3) \\ \mathrm{N}(4) \# 1-\mathrm{Cd}(1)-\mathrm{N}(9) & 94.6(4) \\ \mathrm{N}(4) \# 1-\mathrm{Cd}(1)-\mathrm{N}(7) & 88.1(3)\end{array}$

$\mathrm{N}(7)-\mathrm{Cd}(1)-\mathrm{N}(6) \# 1$

$2.237(2)$
$2.322(2)$
$2.419(2)$
$2.194(2)$
$2.372(2)$
$2.382(2)$
$95.48(10)$
$95.82(9)$
$91.34(8)$
$69.18(7)$

$\mathrm{Cd}(1)-\mathrm{N}(7)$

$\mathrm{Cd}(1)-\mathrm{N}(3)$

$\mathrm{Cd}(1)-\mathrm{N}(4)$

$\mathrm{Cd}(2)-\mathrm{N}(14)$

$\mathrm{Cd}(2)-\mathrm{N}(15)$

$\mathrm{Cd}(2)-\mathrm{N}(12)$

$\mathrm{N}(2)-\mathrm{Cd}(1)-\mathrm{N}(10)$

$\mathrm{N}(3)-\mathrm{Cd}(1)-\mathrm{N}(10)$

$\mathrm{N}(13)-\mathrm{Cd}(2)-\mathrm{N}(16)$

$\mathrm{N}(16)-\mathrm{Cd}(2)-\mathrm{N}(6) \# 1$
2.299(14)

2.396(15)

2.453(14)

88.01(6)

$89.77(6)$

$75.21(5)$

69.28(5)

2.299(2)

2.404(2)

2.483(2)

2.317(2)

2.377(2)

2.578(2)

$160.82(8)$

$119.86(8)$

93.49(9)

96.48(10)

each Cd(II) ion is fulfilled by one tridentate Schiff base ligand $\left(\mathbf{L}^{\mathbf{1}}\right)$, one terminal azido ion and two bridging azido ions (Fig. 2). Two bridging azido ions make a bridge between two $\mathrm{Cd}(\mathrm{II})$

centers through a $\mu-1,1$ double bridged end-on fashion. Though there are some coordination angles [N4-Cd1-N4 $\left(72.5^{\circ}\right)$; N7Cd1-N8 $\left(68.1^{\circ}\right)$; N8-Cd1-N9 $\left.\left(73.8^{\circ}\right)\right]$ deviating considerably from $90^{\circ}$, however, this can be attributed to the chelating nature of Schiff base ligand and bridging nature of azido ion. The bond lengths between $\mathrm{Cd}$ atom and $\mathrm{N}$-donor centers are within the range of 2.23(2)-2.41(1) $\AA$ (Table 2), similar to earlier report. ${ }^{44}$ Each dimeric unit is linked with each other via $\mathrm{C} 4-\mathrm{H} 4 \cdots \mathrm{N} 3$ hydrogen bonding (Fig. 2) to make a 1D chain like structure along $c$-axis (Fig. 2).

\subsection{Crystal structure of complex 4}

Compound 4 forms a 1D coordination polymeric zig-zag chain along $c$-axis. Two crystallographically same cadmium centers (Cd1) alternate along the chain (Fig. 3). Each cadmium atom is coordinated in distorted octahedral fashion by three nitrogen donors from tridentate chelating Schiff base ligand $\left(\mathbf{L}^{2}\right)$, one terminal azido ion and two nitrogen donors from two bridging (crystallographically different) azido ligand. These two azido ligands are responsible to make this coordination polymer making a bridge between two crystallographically same cadmium centers via a $\mu-1,3$ end-end fashion. Two such $1 \mathrm{D}$ coordination polymeric chains are further connected via C2$\mathrm{H} 2 \cdots \mathrm{O} 1$ hydrogen bonding to make a 2D sheet-like structure (Fig. 3).

\subsection{Crystal structure of complex 5}

Compound 5 forms again a 1D coordination polymeric zig-zag chain along $c$-axis. The smallest unit of this polymeric complex is a dimer unit which contains crystallographically two different cadmium ions. Each cadmium atom is coordinated in distorted octahedral fashion by three nitrogen donors from tridentate chelating Schiff base ligand $\left(\mathbf{L}^{3}\right)$ and three azido ligand (Fig. 4). Two different kind of azido ligand makes the bridge in $\mu-1,3$ end to end fashion between two adjacent cadmium pairs to form the $1 \mathrm{D}$-coordination polymeric structure.

\subsection{Electrochemical studies}

Electrochemical studies have been carried out to measure the corrosion inhibition property of the above said complexes. Initially, we have tested the corrosion inhibition property of complex 1 which was not showing significant inhibition property with comparison of parental ligand $\mathbf{L}^{\mathbf{1}}$ and other precursor moieties. Therefore we have introduced another coligand in

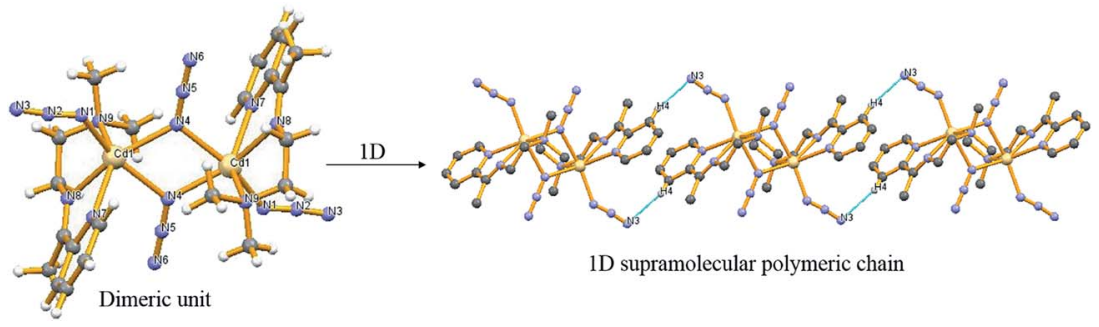

Fig. 2 Dimeric unit structure and supramolecular network structure of complex 3. 


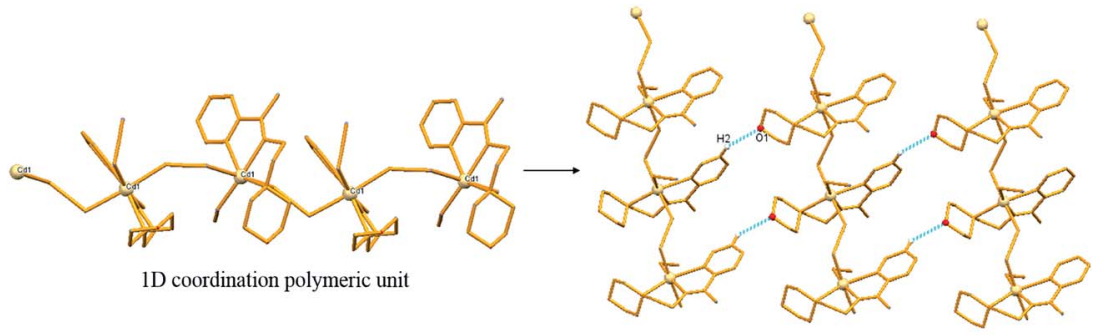

2D supramolecular structure

Fig. 3 Coordination polymeric structure and 2D supramolecular network of complex 4 .

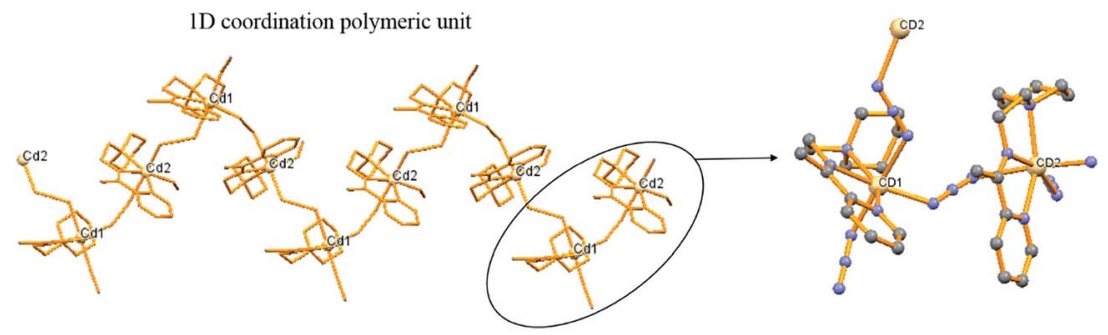

Fig. 4 1D coordination polymeric structure of complex 5

metal Schiff base complex in the form of cyanoacetate to study the corrosion inhibition property in complex 2 . Unfortunately, this complex was also showing very little activity. Therefore it has been planned to introduce azide as a coligand which is having many $\mathrm{N}$ atoms which can act as donor sites. Interestingly, in that case, the synthesized complex 3 has shown the considerable corrosion inhibition property. Encouraged by this results we tried to employ different Schiff base ligands to explore the best possible combination for this kind of activity. Ligand $\mathbf{L}^{2}$ and $\mathbf{L}^{3}$ provided us complex $\mathbf{4}$ and $\mathbf{5}$ respectively, which have shown good corrosion inhibition in $15 \% \mathrm{HCl}$ medium. The enhanced corrosion inhibition property in 3-5 may be due to the greater availability of $\mathrm{N}$ absorbing sites in azide molecules. Cd complexes diminish the corrosion process which was revealed by the polarization and impedance studies. These studies were performed after stabilization of open circuit potential (OCP).

\subsection{Open circuit potential}

The variation of open circuit potential $\left(E_{\text {ocp }}\right)$ with time for mild steel in $15 \% \mathrm{HCl}$ without and with the addition of different concentrations of $\mathrm{Cd}$ (II) complexes is shown in Fig. S4. $\dagger$ The figures clearly indicate that stable OCP values were attained after $1 \mathrm{~h}$ of immersion, both in the absence and presence of the inhibitors. A concentration-dependent positive shift of corrosion potential with respect to the blank was observed on the addition of Cd(II) complexes into the corrosive medium. This indicates a probable impact on both anodic and cathodic polarization. ${ }^{46}$

\subsection{Potentiodynamic polarization measurements}

The polarization curves for mild steel electrode in $15 \% \mathrm{HCl}$ solution were performed without and with inhibitors (Cd complex 3, 4 \& 5) at various concentrations. The effect of different concentrations of $\mathrm{Cd}$ complexes in corrosion inhibition is shown in Fig. 5. The Tafel curves were generated after 1 hour of immersion in the test solution as a combination of anodic and cathodic polarization curves. All potentiodynamic polarization parameters such as corrosion current density $\left(i_{\text {corr }}\right)$, corrosion potential $\left(E_{\text {corr }}\right)$, anodic $\left(\beta_{\mathrm{a}}\right)$ and cathodic $\left(\beta_{\mathrm{c}}\right)$ Tafel slopes acquired from these curves and the calculated inhibition efficiency $\left(\eta_{\text {pol }}(\%)\right)$ values are listed in Table 3 . The $i_{\text {corr }}$ values were obtained by extrapolation of liner section of both Tafel curves. The following eqn (7) has been used to calculate the efficiency $\left(\eta_{\text {pol }}(\%)\right)$

$$
\eta_{\text {pol }}(\%)=\frac{i_{\text {corr }}^{0}-i_{\text {corr }}}{i_{\text {corr }}^{0}} \times 100
$$

where, $i_{\text {corr }}^{0}$ and $i_{\text {corr }}$ are corrosion current densities $\left(\mu \mathrm{A} \mathrm{cm}^{-2}\right)$ without and with inhibitor. The order of inhibition efficiency of those Cd complexes is $\mathbf{4}>\mathbf{5}>\mathbf{3}$.

There is no significant trend observed in the shift of $E_{\text {corr }}$ values as well as $\beta_{\mathrm{a}} \& \beta_{\mathrm{c}}$ values on the addition of inhibitor with respect to that without inhibitor. In the present study, it was observed that all inhibitors in $15 \% \mathrm{HCl}$ solution exhibited anodic as well as cathodic inhibition effect i.e. 'mixed type with predominantly anodic inhibitor ${ }^{47,48}$ as the difference of $E_{\text {corr }}$ values between blank and in presence of inhibitors lies within $\pm 85 \mathrm{mV} v s$. SCE with shifting of $E_{\text {corr }}$ towards more anodic region. The inhibition efficiency depends on several aspects like interaction mode, adsorption center, structure and size. ${ }^{31}$ The corrosion inhibition efficiency was increased with the increasing concentration of inhibitor and the maximum efficiencies were shown at $0.1 \mathrm{~g} \mathrm{~L}^{-1}$ as listed in Table 3 . 

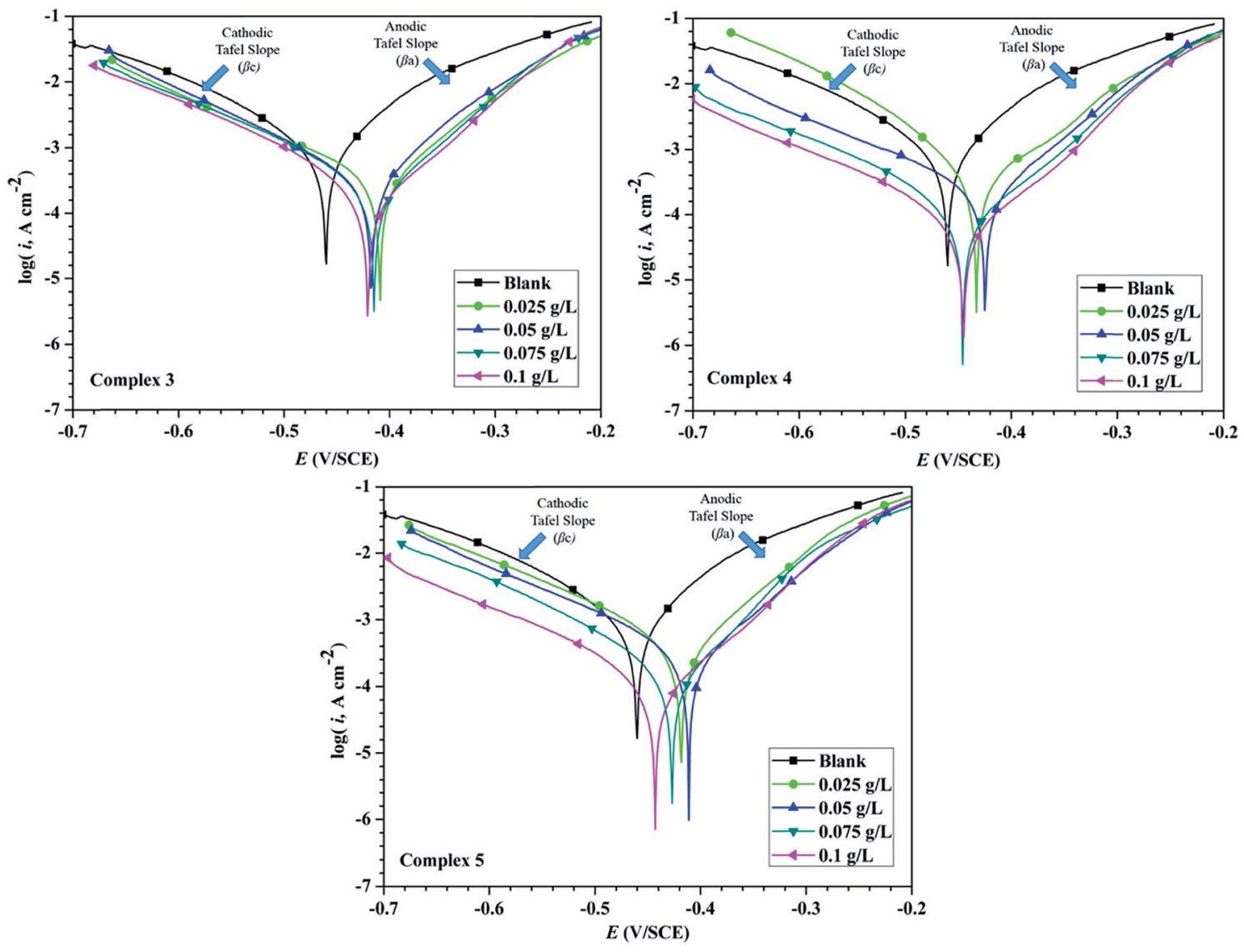

Fig. 5 Polarization curves for mild steel in $15 \% \mathrm{HCl}$ solution with and without various concentrations of inhibitors 3, 4 and 5.

Table 3 Electrochemical parameters of potentiodynamic polarization studies with and without inhibitor in $15 \% \mathrm{HCl}$ at $298 \pm 1 \mathrm{~K}$

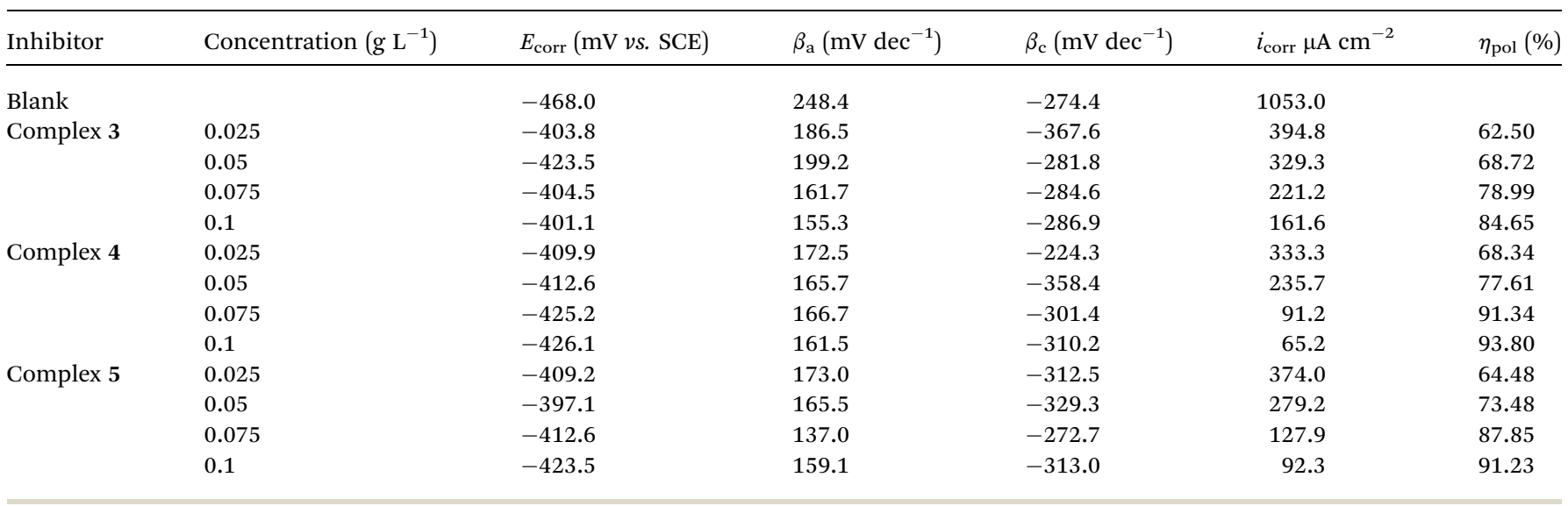

\subsection{Impedance studies}

The corrosion of mild steel was also studied with the help of EIS technique. The Nyquist plots of mild steel sample with and without inhibitors (Cd(II) Schiff base complexes) in 15\% hydrochloric acid medium are shown in Fig. 6. This shows a single capacitive loop in the frequency range $100 \mathrm{kHz}$ to 10 $\mathrm{mHz}$, which arises from the one time constant in impedance spectroscopy. In higher frequency range assigned with the charge transfer resistance and lower frequency was attributed to film resistance which was formed by inhibitor layer. ${ }^{49,50}$ In our case in presence of inhibitor a very thin film was formed on the metallic surface throughout the adsorption process. Nyquist plots for mild steel in uninhibited solution are semi-circular in nature, but in the presence of inhibitors, the shape of the semicircle is depressed due to the frequency dispersion and microscopic roughness of the electrode surface. 

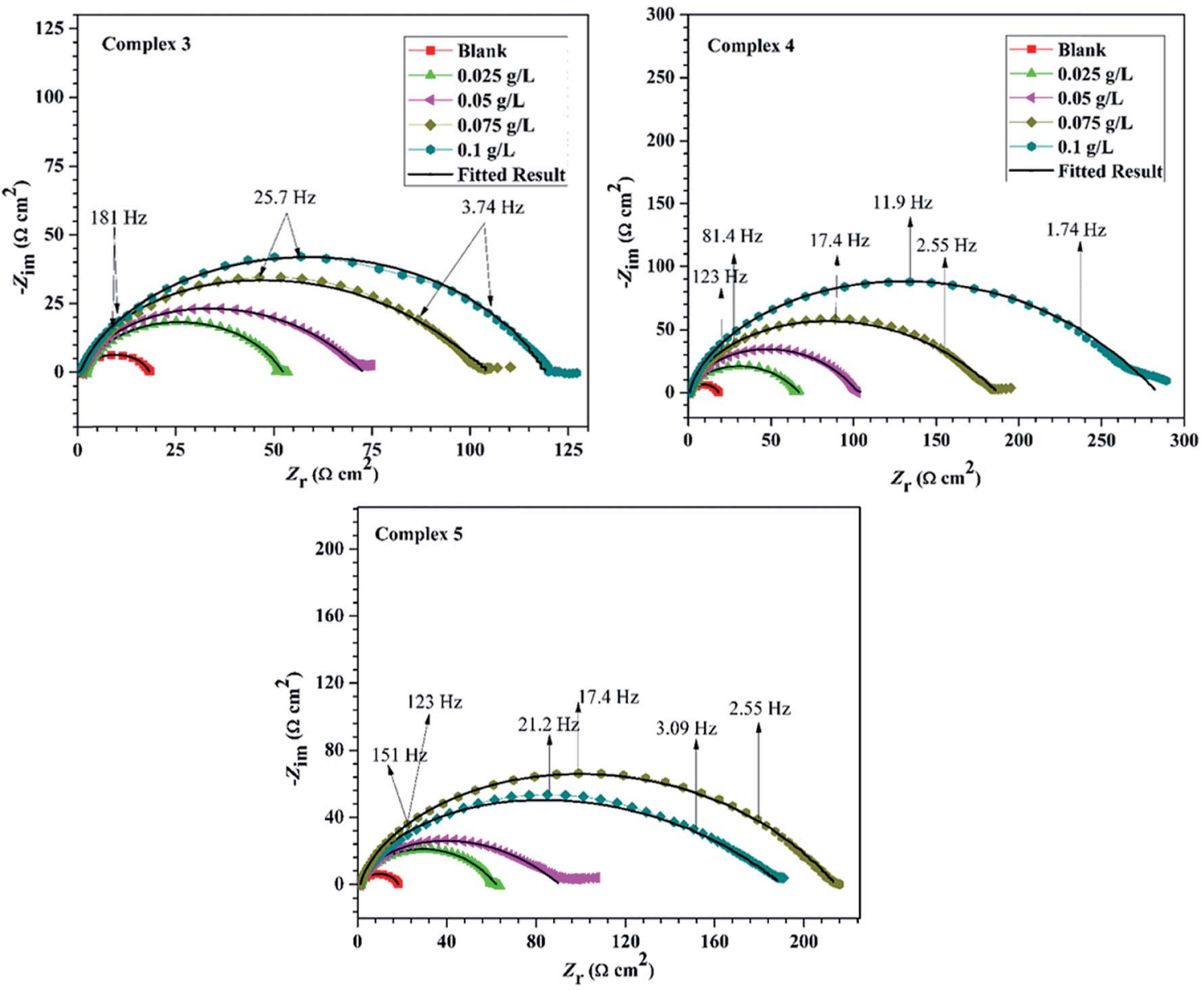

Fig. 6 Nyquist plots for mild steel in $15 \% \mathrm{HCl}$ in the absence and presence of different concentrations of all three inhibitors 3,4 and 5 at $298 \pm 1 \mathrm{~K}$.

The semi-circular Nyquist plot of uninhibited solution indicates that the corrosion process of mild steel was controlled by the charge transfer resistance. But the depressed semicircular Nyquist plot in the presence of inhibitors is considered as the polarization resistance $\left(R_{\mathrm{p}}\right)$ between the metal and outer Helmholtz plane. In this case, polarization resistance $\left(R_{\mathrm{p}}\right)$ containing all the resistances between metal and solution interfaces were included. Those are mainly charge transfer resistance $\left(R_{\mathrm{ct}}\right)$, film resistance $\left(R_{\mathrm{f}}\right)$, accumulation resistance $\left(R_{\mathrm{a}}\right)$, diffuse layer resistance $\left(R_{\mathrm{d}}\right)$ etc. ${ }^{51}$ The shape and size of depressed semicircle was gradually increased with the addition of inhibitor up to $0.1 \mathrm{~g} \mathrm{~L}^{-1}$ concentrations. This increase in the diameter of the semicircle shows that the $R_{\text {ct }}$ was increasing with increasing concentration of inhibitors. This phenomenon defined the protective layer formation on the metal surface and the consequent reduction in the metal dissolution. Furthermore, Bode plots can give more information in case of more intricate systems. The Bode plots of the synthesized inhibitors are presented in Fig. 7. To compare corrosion resistance of different samples, one important parameter i.e., low-frequency impedance modulus $Z_{\text {mod }}$ can be used. ${ }^{24}$ Increase in $Z_{\text {mod }}$ demonstrates better protection performance as reported earlier. ${ }^{52}$ Fig. 7 showed that $Z_{\text {mod }}$ increased as a function of the concentration for the synthesized inhibitor.
The phase angle plots for the mild steel in the presence and absence of inhibitors in $15 \% \mathrm{HCl}$ are given in Fig. 8. These also reinforce the inferences from Nyquist and Bode plots.

The impedance studies on double layer capacitance in inhibited solutions have shown deviation from ideal behavior. This scattering has been attributed to roughness and other inhomogeneities of the mild steel electrode and also due to anion adsorption. The uncharacteristic capacitance can be represented by a constant phase element (CPE), ${ }^{10}$ and the impedance $\left(Z_{\mathrm{CPE}}\right)$ can be expressed by eqn (7):

$$
Z_{\mathrm{CPE}}=\frac{1}{Y_{0}(j w)^{n}}
$$

where, $Y_{0}$ is the quantity of CPE, $j$ is the imaginary unit $\left(j^{2}=-1\right)$, $n$ is the phase shift parameter that belongs to $0<n<1$, and $w$ is the angular frequency in $\mathrm{Hz}$. The depressed semicircle can be explained by this $n$ value. The value in the range 0.5 to 1 , implies that the semi-circle is depressed at higher frequency ranges. The $n$ value is a measure of the in-homogeneity or roughness of the solid surface. ${ }^{53}$ The impedance parameter $\left(R_{\mathrm{s}}, R_{\mathrm{ct}}, R_{\mathrm{p}}, R_{\mathrm{f}}, n\right.$, $\left.Y_{0} \& C_{\mathrm{dl}}\right)$ are evaluated with the equivalent circuit fitting program. The EIS plots analyzed by software $\mathrm{CHI}$ instrument software and obtained the required data. ${ }^{54}$ The equivalent circuit, in the absence of inhibitor, is shown in Fig. 9. 

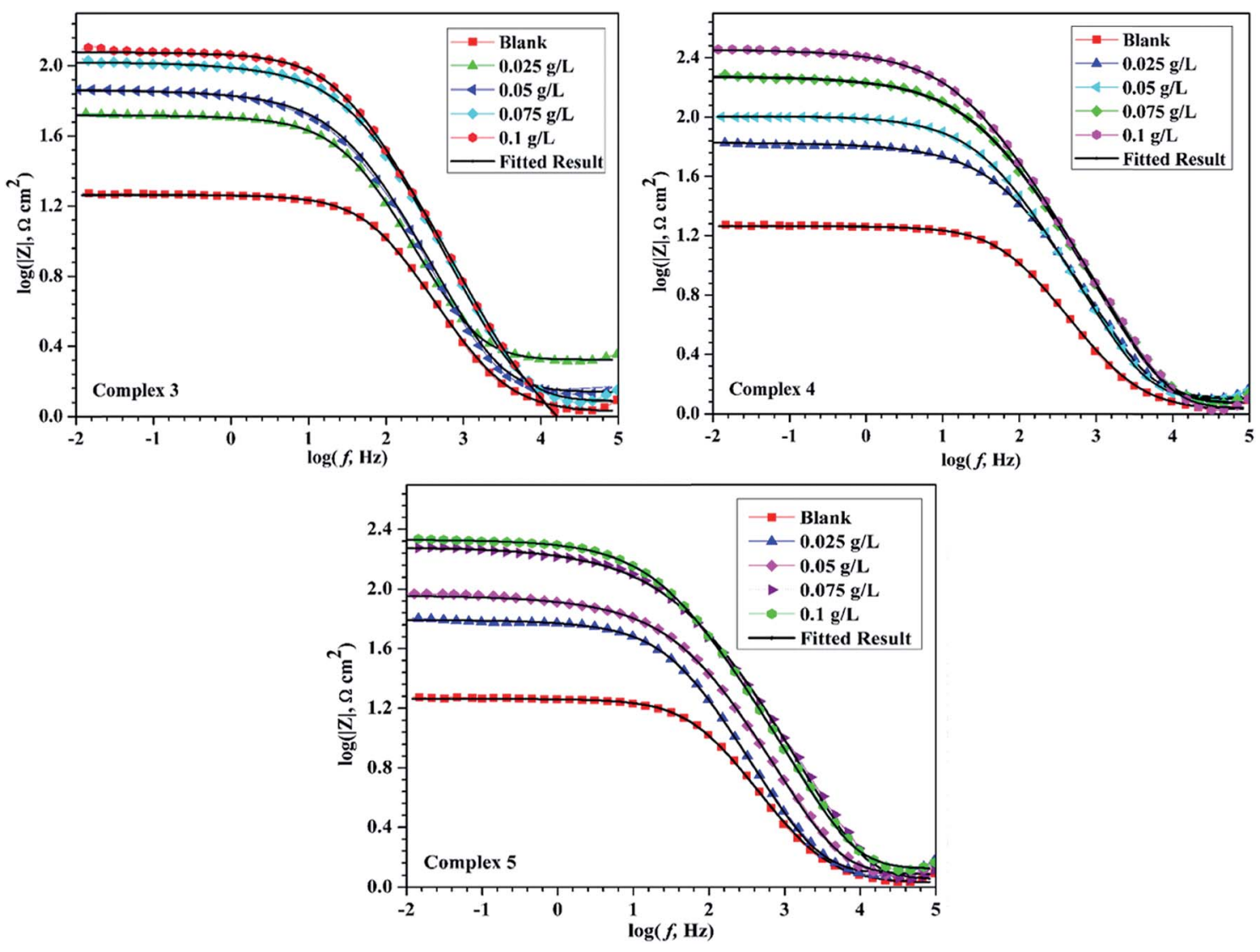

Fig. 7 Bode plot of mild steel in $15 \% \mathrm{HCl}$ without and with various concentrations of inhibitors.

Here, the resistance is considered as charge transfer resistance and include all other ions or any kinds of corrosion product. The equivalent circuit is changed for the system in the presence of inhibitor as shown in Fig. 10. In this behavior of metallic electrode, the parallel network: charge transfer resistance-double layer capacitance is established in presence of inhibitor.

The corrosion inhibition efficiency was calculated using the charge transfer resistance $\left(R_{\mathrm{ct}}\right)$ value using the following formula eqn (8):

$$
\eta_{\text {imp }}(\%)=\frac{R_{\mathrm{p}}-R_{\mathrm{p}}^{0}}{R_{\mathrm{p}}} \times 100
$$

where, $R_{\mathrm{p}}^{0}$ and $R_{\mathrm{p}}$ are polarization resistances of mild steel in the absence and presence of the inhibitor respectively. The $R_{\mathrm{p}}$ values are observed to be linearly proportional to the concentrations of inhibitor molecules. The maximum inhibition efficiency $93.89 \%$ was found for Cd complex 4 at $0.1 \mathrm{~g} \mathrm{~L} \mathrm{~L}^{-1}$ concentration and other two Cd complexes 3 and 5 showed efficiency at this concentration of $84.95 \%$ and $91.88 \%$ respectively (Table 4$)$. The double layer capacitance $\left(C_{\mathrm{dl}}\right)$ values were calculated from CPE parameter values $Y_{0}$ and $n$, using the eqn (9),

$$
C_{\mathrm{dl}}=Y_{0}{ }^{1 / n}+R_{\mathrm{ct}}^{(1-n) / n}
$$

where, $Y_{0}$ and $n$ are magnitudes of CPE and deviation parameter $(-1 \leq n \leq 1$, which is dependent on surface morphology).

The $C_{\mathrm{dl}}$ values, generally, are inversely proportional to the adsorbent concentration on the metal surface.

Thus both the results obtained from PC and EIS methods are showing similar kind of efficiency trend among these three complexes. The higher efficiency of polymeric complexes ( 4 and 5) than dimeric complex 3 may be due to the higher availability of adsorbing $\mathrm{N}$-donor sites as more number of azides were attached in the polymeric complexes. Among the two polymeric complexes, complex 4 is showing slightly higher inhibition efficiency, may be because of the presence of non-coordinated $\mathrm{O}$ donor adsorbing site.

\subsection{Adsorption isotherm}

The adsorption isotherms gives noteworthy information about the interaction happening between the inhibitors molecules and metal surfaces. In $15 \% \mathrm{HCl}$ medium, mild steel is surrounded by polar water molecules and other ions present. Therefore the adsorption of inhibitor molecules occur through substitution of water molecules which were previously attached to the metal surface via mainly two categories of adsorption processes. First one is chemisorption, where donor-acceptor type of irreversible interactions take place via forming a coordinate bond between metal surface and inhibitor molecule. The second one is physisorption, here the inhibitor molecules 

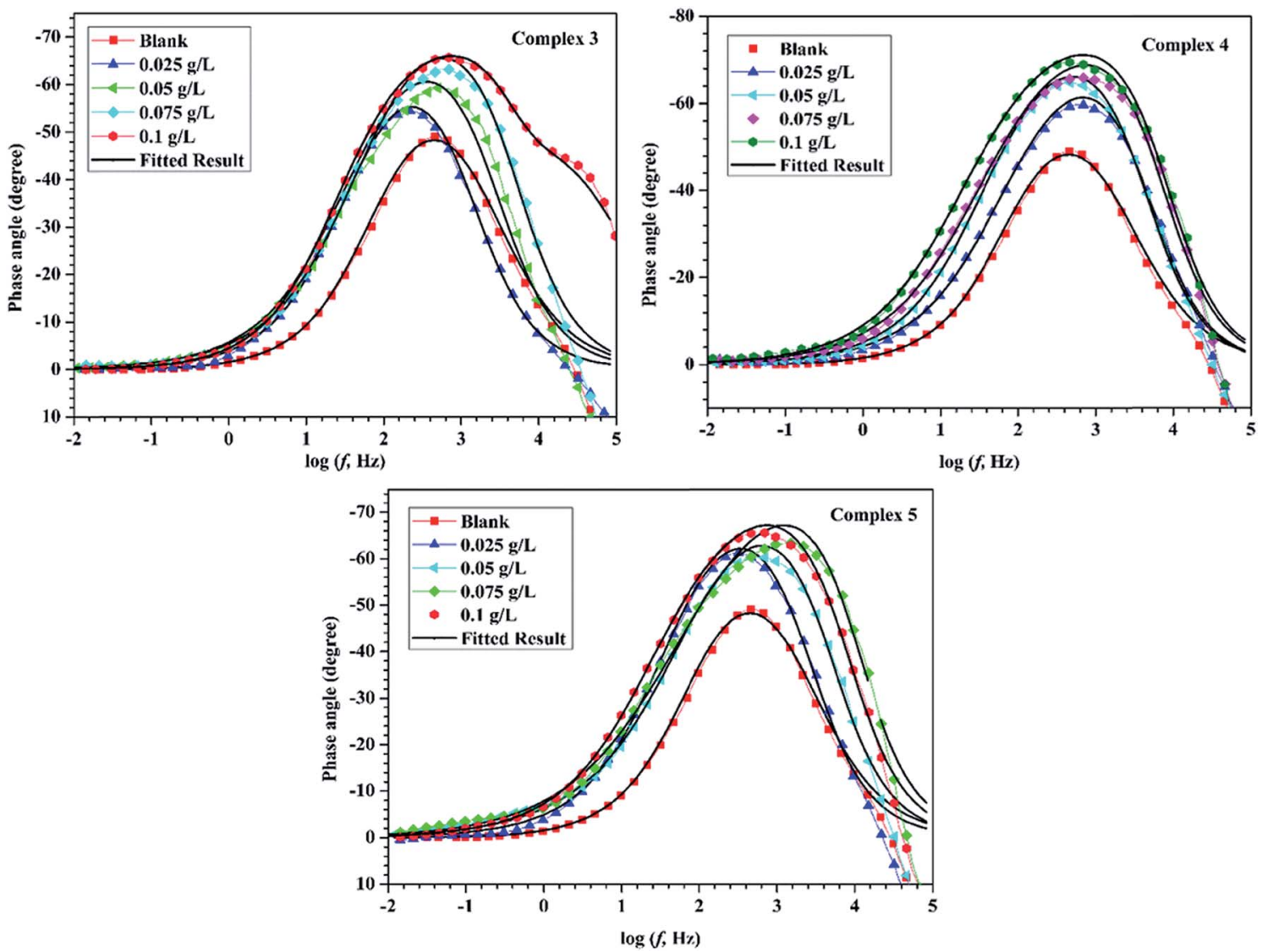

Fig. 8 Phase angle plots of mild steel in $15 \% \mathrm{M} \mathrm{HCl}$ solutions without and with various concentrations of inhibitor.

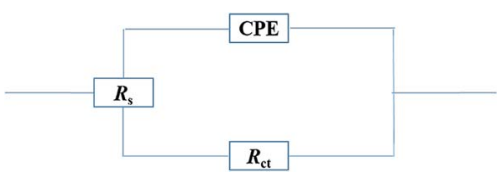

Fig. 9 Equivalent circuits used to fit EIS data of mild steel in $\mathrm{HCl}$ medium without inhibitor.

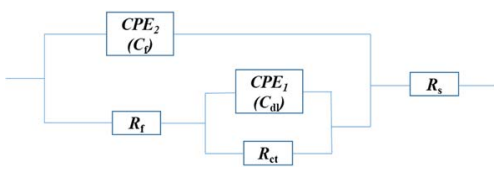

Fig. 10 Equivalent circuits (with inhibitor) used to fit the EIS data of mild steel in $\mathrm{HCl}$ medium.

adsorb on the concerned metallic surfaces by the electrostatic interaction. Adsorption of inhibitor molecules also indicates that the interaction force between metal-inhibitor is greater than that of metal-water. The surface coverage $(\theta)$ was calculated from the $R_{\mathrm{p}}^{0}$ and $R_{\mathrm{p}}$ values by the following eqn (10):

$$
\theta=\frac{R_{\mathrm{p}}-R_{\mathrm{p}}^{0}}{R_{\mathrm{p}}}
$$

The obtained data were tested for Langmuir adsorption isotherm, which can be represented by the eqn (11),

$$
\frac{C}{\theta}=\frac{1}{K_{\mathrm{ads}}}+C
$$

where, $K_{\text {ads }}$ is the adsorption-desorption equilibrium constant and $C$ is adsorbent concentration. For $\mathbf{3 ,} \mathbf{4}$ and $\mathbf{5}$, straight lines were obtained from the plots of $C / \theta \mathrm{vs}$. $C$ with a high correlation coefficient $\left(r^{2}\right)$ value of $0.998,0.998$ and 0.996 for 3,4 and 5 respectively at $298 \pm 1 \mathrm{~K}$ (Fig. 11). The values of $K_{\text {ads }}$ in association with the standard Gibbs free energy of adsorption $\Delta G_{\text {ads }}^{0}$ was obtained from the Langmuir adsorption isotherm by the following eqn (12),

$$
K_{\text {ads }}=\frac{1}{C_{(\text {sol. })}} \exp \left(\frac{\Delta G_{\text {ads }}^{0}}{R T}\right)
$$

where, $R$ is the universal gas constant, $T$ is the absolute temperature and $C_{\text {(sol.) }}$ is the conc. of water $\left(1000 \mathrm{~g} \mathrm{~L}^{-1}\right)$. The values of $K_{\mathrm{ads}}$ is represented here in $\mathrm{g}^{-1} \mathrm{~L}$, thus in this equation the conc. of water is taken in $\mathrm{g} \mathrm{L}^{-1}\left(1000 \mathrm{~g} \mathrm{~L}^{-1}\right)$ in place of 55.5 mole $\mathrm{L}^{-1}{ }^{40,54}$ In general when the obtained $\Delta G_{\text {ads }}^{0}$ values of inhibitor lies in the order of $-20 \mathrm{~kJ} \mathrm{~mol}^{-1}$ or even lower (more positive), it satisfies the electrostatic interaction between inhibitor and metal surface (physisorption type). The $\Delta G_{\text {ads }}^{0}$ values around $-40 \mathrm{~kJ} \mathrm{~mol}^{-1}$ or higher (more negative) are associated with coordinate bond formation (chemisorption 
Table 4 Impedance data for corrosion of mild steel in $15 \% \mathrm{HCl}$ in absence and presence of different concentration of different inhibitor at $298 \pm$ $1 \mathrm{~K}$

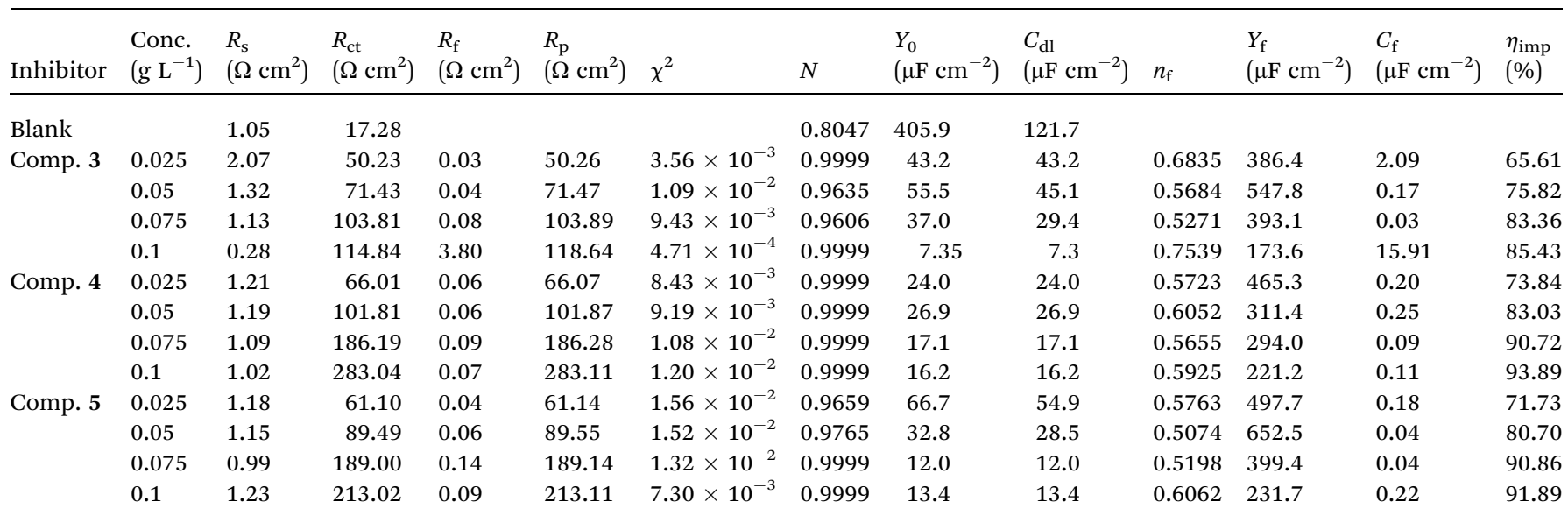

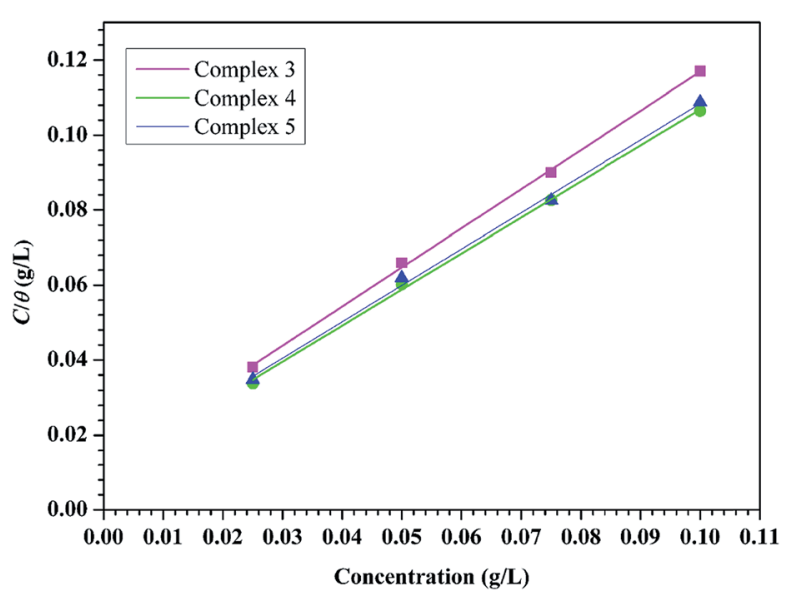

Fig. 11 Langmuir adsorption isotherm of all inhibitors on mild steel surface in $15 \% \mathrm{HCl}$ medium.

type). ${ }^{2}$ However, adsorption of the inhibitor molecules on the metallic surfaces cannot be considered as purely chemical or physical phenomenon. ${ }^{2}$ Apart from chemisorption, inhibitor molecule is also adsorbed on the metallic surfaces via physisorption. ${ }^{55,56}$

The obtained $\Delta G_{\text {ads }}^{0}$ values of our synthesized inhibitors are $-27.96 \mathrm{~kJ} \mathrm{~mol}^{-1},-28.35 \mathrm{~kJ} \mathrm{~mol}^{-1}$ and $-28.20 \mathrm{~kJ} \mathrm{~mol}^{-1}$ for complex 3, 4 and 5 respectively. The above range of $\Delta G_{\text {ads }}^{0}$ values designate the contribution of physisorption along with chemisorption. Thus it can be concluded that inhibitor molecules were adsorbed on the metallic surface following a mixed type adsorption phenomenon.

\subsection{Weight loss measurement}

The results obtained from different electrochemical measurements are verified by the weight loss measurement. The effect of inhibitors at various concentrations is shown in Fig. S5 and Table S1. $\dagger$ The inhibition efficiency $\left(\eta_{\mathrm{wt}} \%\right)$ increased with increase in inhibitor concentrations. Table $\mathrm{S} 1 \uparrow$ shows that at
$0.1 \mathrm{~g} \mathrm{~L}^{-1}$ complex 4 shows maximum inhibition efficiency. All the trends of inhibition efficiencies obtained from weight loss measurement are quite comparable with the results obtained from other electrochemical experiments. The higher efficiency of complex 4 may be due to the fact that it covered the metal surface efficiently and thus retarded the dissolution of mild steel. $^{54}$

\subsection{Surface morphology study}

The surface morphology of the mild steel sample in $15 \% \mathrm{HCl}$ solution in the absence and presence of inhibitors of optimum concentration $\left(0.1 \mathrm{~g} \mathrm{~L}^{-1}\right)$ is shown in Fig. 12. Significant corrosion damage can be clearly observed when metal was kept immersed in 15\% $\mathrm{HCl}$ solution for $1 \mathrm{~h}$ and $6 \mathrm{~h}$ respectively without inhibitor (Fig. S6† and Fig. 12). From both the images it was quite clearly visible that the surface roughness of mild steel increases in acidic medium with time in absence of inhibitor molecule. However, in the presence of inhibitors, uniformity and smoothness of metal surface improved remarkably with time (Fig. 12 and Fig. S6†). So it can be concluded that corrosive attack is considerably reduced by the inhibitor molecules in comparison with blank, indicating high-efficiency protective film on the mild steel surface are formed by these cadmium Schiff base complexes.

\subsection{Stability study in acidic media and on steel surface}

There are several examples of corrosion inhibition of mild steel in acidic medium using coordination complexes including metal Schiff base complexes. ${ }^{27,28,57,58}$ In spite of previous reports which support the intactness of entire coordination complexes in the application medium, dissimilarities in the inhibition efficiency of our synthesized complexes indirectly indicate that this inhibition is not due to the formation of fragmented species of complexes in the medium. Furthermore, ESI-MS, UVVis and FTIR results in case of complex 3 before and after treatment with $15 \% \mathrm{HCl}$ also clearly show the integrity of the complex in 15\% $\mathrm{HCl}$ medium. Complex 3 was chosen for this 


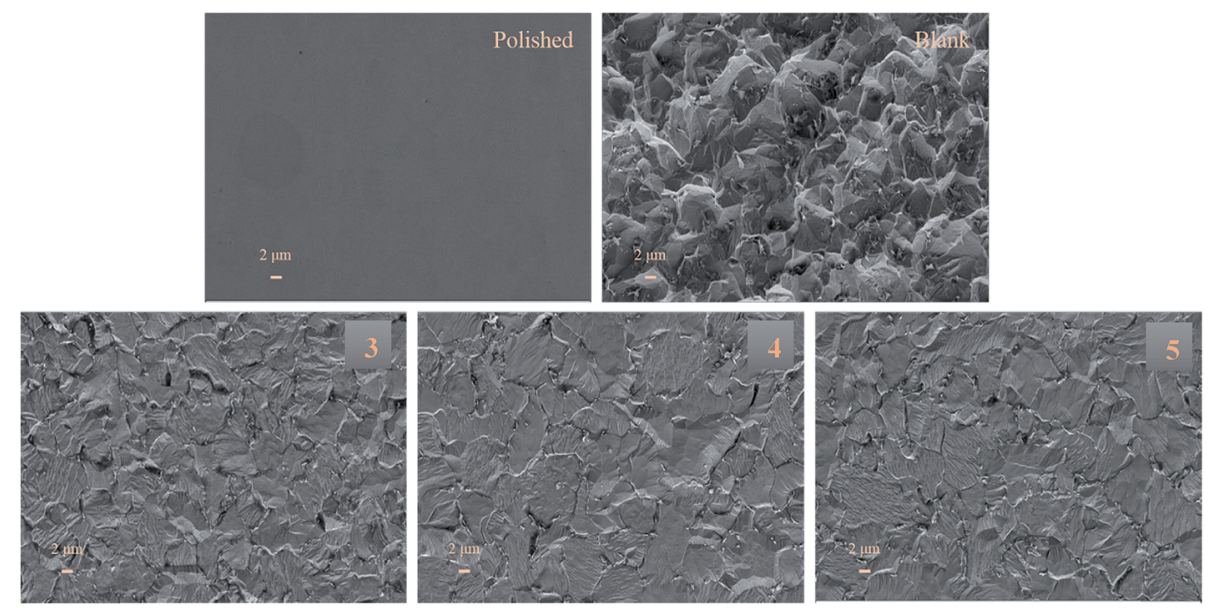

Fig. 12 FE-SEM images of mild steel in $15 \% \mathrm{HCl}$ solution at $298 \pm 1 \mathrm{~K}$, polished: before immersion; blank: in the absence of inhibitors and presence of inhibitor $3,4, \& 5$ at $0.1 \mathrm{~g} \mathrm{~L}^{-1}$ after $6 \mathrm{~h}$ of immersion.

study due to its fixed molar mass because of its dimeric nature. If complex $3\left(0.1 \mathrm{~g} \mathrm{~L}^{-1}\right)$ get destroyed in the acidic medium then it may form new species like free ligands $\left(0.04 \mathrm{~g} \mathrm{~L}^{-1}\right)$, azide ions $\left(0.02 \mathrm{~g} \mathrm{~L}^{-1}\right)$, cadmium chloride $\left(0.04 \mathrm{~g} \mathrm{~L}^{-1}\right)$ or precursor of ligands i.e., ketone $\left(0.03 \mathrm{~g} \mathrm{~L}^{-1}\right)$ and amine $\left(0.02 \mathrm{~g} \mathrm{~L}^{-1}\right)$. Thus, this fixed molar mass of complex 3 is an essential tool to understand about the species which is responsible factor for corrosion inhibition in acidic medium.

ESI-MS spectra of a single crystal of complex 3 in water had $\mathrm{m} / \mathrm{z}$ peak at 347.07 for $\left[\mathrm{Cd}_{2}\left(\mathbf{L}^{\mathbf{1}}\right)_{2}\left(\mathrm{~N}_{3}\right)_{2}\right]^{2+}$. After addition of $15 \%$ $\mathrm{HCl}$, the $m / z$ peak was observed at 347.1 which demonstrate the stability of complex in acidic medium (Fig. S7, ESI†). Furthermore solid state and solution $(15 \% \mathrm{HCl})$ state UV-Vis spectra, as well as IR spectra, indicate the stability of the complex in acidic medium (Fig. S8 and S9, ESI $\dagger$ ). Almost similar XRD pattern obtained for the powder form of complex 3 and the thin film made after treatment with $15 \% \mathrm{HCl}$ indicate the intactness of crystalline structure of the complex in the medium (Fig. S10, ESI†). The deviation in peak intensity ratio arises may be due to the temperature effect on preparation of thin films.

Still, electrochemical studies of ligand $\mathbf{L}^{\mathbf{1}}$, azide $\left(\mathrm{NaN}_{3}\right)$, cadmium chloride, 2 -acetyl pyridine and $\mathrm{N}, \mathrm{N}$-dimethyl ethylene diamine were preformed taking the same conc. $\left(0.1 \mathrm{~g} \mathrm{~L}^{-1}\right)$ of all to quantify the effect on corrosion inhibition if destruction of complex 3 occurs in acidic medium. All the data (Tables S2, S3 and $\dagger$ Fig. S11-S14, ESI $\dagger$ ) show less inhibition efficiency for the constituents compared to complex 3. Furthermore cadmium chloride salt is corrosive in nature which was reported in an earlier report. ${ }^{59}$

Furthermore to scrutinize the composition of adsorbed inhibitor molecule, we performed the EDX analysis of the metal surface after $1 \mathrm{~h}$ of immersion in the acidic medium containing complex 3 (representative purpose). From the Fig. S15† it is clearly evident the presence of all elements of the inhibitor molecule on the mild steel surface. Thus it may be concluded that the whole metal complex is responsible for anti-corrosive film formation on the iron surface.
These phenomena clearly indicate the potential role of the Cd complexes in corrosion inhibition.

\subsection{Quantum chemical calculations}

On the basis of the HSAB (hard-soft-acid-base) ${ }^{60,61}$ and the frontier-controlled interaction concepts, ${ }^{61,62}$ the bonding capabilities of the inhibitors towards the metal atom, Fe, can be well explained. According to HSAB principle, hard acids prefer to coordinate to hard bases and soft acids prefer to co-ordinate to soft bases. Metal atoms like Fe which are known as soft acids when binds with hard molecules it provides a larger HOMOLUMO gap compared to binding a soft molecule where a smaller HOMO-LUMO gap is expected..$^{63-65}$ For representative purpose to compare inhibitory activity between polymeric complexes and dimeric complex only one polymeric complex 4 and one dimeric complex 3 have been taken for quantum chemical calculations and that suggests that the HOMO-LUMO gap for complex 4 is smaller than that of complex 3 which indicates that complex 4 is softer than complex 3 (Table 5). The order of this band gap values is similar with the optical band gap values obtained from UV/Vis experiment. Hence complex $\mathbf{4}$ has higher binding tendency than complex 3 towards Fe. Similarly using the concept of MO (molecular orbital) theory: since the cadmium complexes (inhibitor) is the electron pair donor and the Fe atom is the electron pair acceptor, the energy difference of the HOMO (LUMO is nothing special) of the complexes and the LUMO (HOMO is nothing special) of the Fe (i.e. $-0.12376 \mathrm{eV}$ reported in literature ${ }^{66}$ ) must be considered. The theory proposes that the overlap between the LUMO (Fe) and the HOMO (complex) is a foremost feature in bonding; the lower the HOMO-LUMO energy difference the higher the HOMOLUMO overlap and the stronger the inhibitor-Fe interaction. ${ }^{66}$ Another way to compare inhibition competence with constraints of molecular structure is to compute the fraction of electrons transferred from inhibitor to metal surface. According to Koopman's theorem, ${ }^{67} E_{\text {Номо }}$ and $E_{\mathrm{LUMO}}$ of the inhibitor molecule are related to the ionization potential $(I)$ and the 
Table 5 Calculated quantum chemical parameters of the inhibitor molecules

\begin{tabular}{|c|c|c|c|c|c|c|c|c|}
\hline Basis set & Inhibitor & $E_{\text {номо }}(\mathrm{eV})$ & $E_{\text {LUMO }}(\mathrm{eV})$ & $\Delta E(\mathrm{eV})$ & $\begin{array}{l}E_{\mathrm{LUMO}(\mathrm{Fe})}- \\
E_{\mathrm{HOMO}(\mathrm{inh})}(\mathrm{eV})\end{array}$ & $\chi(\mathrm{eV})$ & $\eta(\mathrm{eV})$ & $\Delta N$ \\
\hline LANL2MB & Comp. 3 & -7.140 & -4.513 & 2.626 & 7.016 & 5.826 & 1.313 & 0.446 \\
\hline \multirow[t]{2}{*}{$3-21 G$} & Comp. 3 & -4.445 & -2.070 & 2.375 & 4.322 & 3.257 & 1.187 & 1.575 \\
\hline & Comp. 4 & -2.465 & -0.242 & 2.223 & 2.342 & 1.353 & 1.111 & 2.540 \\
\hline
\end{tabular}

electron affinity $(A)$, respectively. The ionization potential and the electron affinity are defined as $I=-E_{\text {Номо }}$ and $A=-E_{\mathrm{LUMO}}$. The absolute electronegativity $(\chi)$, global hardness $(\eta)$ and softness $(\sigma)$ of the inhibitors molecule are approximated as $[\chi=$ $(I+A) / 2],[\eta=(I-A) / 2]$ and $[\sigma=1 / \eta] .^{68,69}$ From the calculated result (Table 5) it was very clear that softness of complex 4 is higher than complex 3 which supports the previous explanation. Pearson method ${ }^{70}$ was utilized to calculate the fraction of electrons transfer $(\Delta N)$ from the inhibitor to metallic surface using the following eqn (13). ${ }^{71}$

$$
\Delta N=\frac{\chi_{\mathrm{Fe}}-\chi_{\mathrm{inh}}}{2\left(\eta_{\mathrm{Fe}}+\eta_{\mathrm{inh}}\right)}
$$

There are various report for the use of the theoretical value of $\chi_{\mathrm{Fe}}=7 \mathrm{eV}$ and of $\eta_{\mathrm{Fe}}=0 \mathrm{eV}$ to calculate $\Delta N$ in many literature in recent time. ${ }^{61,72}$ The tabulated data (Table 5) shows that the $\Delta N$ values for both the inhibitors are positive and less than 3.6 which means both have capability to donate its electron to the metallic surface. It was also observed that the order of electron transfer is higher in the case of polymeric complex 4 than dimeric complex $\mathbf{3}$ which also confirms that complex $\mathbf{4}$ has the greater tendency to donate electrons and therefore the higher affinity to bind onto the metal surface.

As we have proposed due to more heteroatom availability the polymeric complexes have greater tendency to interact with $\mathrm{Fe}$ surface, thus to investigate this phenomenon theoretically, we employed molecular electrostatic potential (MEP) mapping which provides a visual method to comprehend the location of the electrophilic attack, nucleophilic attack and the electrostatic potential zero regions. ${ }^{73}$ In these maps, different values of the MEP were demonstrated with the help of different colors, which are red, yellow, green, light blue and blue. The red and yellow colors, appropriate for the negative parts of the MEP, are associated to electrophilic reactivity, blue colors appropriate for the positive parts to the nucleophilic reactivity and the green color signifies the ESP zero region. In case of this compounds, it is clear that here red or yellow sites are mainly observed over azido $\mathrm{N}$ atoms. Thus Azido $\mathrm{N}$ atoms are a main responsible factor to interact with the metal surface. These remarks further confirmed by Mulliken charges on the reactive $\mathrm{N}$ atoms. The Mulliken charges on azido $\mathrm{N}$ atoms are more negative in complex 4 than complex 3 which is also a supportive indication of greater inhibition efficiency of polymeric complexes.

This phenomenon is further corroborated with the Fukui indices analysis which is an important strategy to find out which atoms in the molecule mainly participate in this donor acceptor type of interactions. Fukui indices analysis. Fukui indices analysis can sensibly determine the local reactivity as well as the corresponding nucleophilic and electrophilic behavior of the molecule. ${ }^{40}$ The higher value of $f_{\mathrm{k}}{ }^{+}$suggests acceptance of electron from the metal surface and higher value of $f_{\mathrm{k}}{ }^{-}$suggests higher donation ability of inhibitor molecules. ${ }^{40}$ The calculated Fukui indices are presented in Table S4. $\dagger$ And the results indicate that $\mathrm{N}$ and $\mathrm{C}$ atoms of azide and acetyl pyridine moiety are the most susceptible sites for electron acceptance or donation. It was observed a relatively high $f_{\mathrm{k}}{ }^{-}$ values which was observed for the atoms like $\mathrm{N}(4), \mathrm{N}(42), \mathrm{N}(2)$, $\mathrm{N}(40), \mathrm{N}(3), \mathrm{N}(41), \mathrm{N}(7)$ and $\mathrm{N}(45)$ indicate that $\mathrm{N}$ atoms of azide has higher affinity to donate electrons to the steel surface. Besides this a relatively higher $f_{\mathrm{k}}{ }^{+}$values associated with $\mathrm{N}(4)$, $\mathrm{N}(42), \mathrm{C}(13), \mathrm{C}(51), \mathrm{C}(15)$ and $\mathrm{C}(53)$ atoms in complex 3 indicate terminal $\mathrm{N}$ atoms of azide and $\mathrm{C}$ atoms lies in the pyridine ring are responsible for accepting electron from the mild steel surface. From the table it was also clearly seen that $\operatorname{Cd}(1)$ and $\operatorname{Cd}(39)$ have tendency to accept electron from steel surface. Similarly the $\mathrm{N}$ atoms located in the azide part of complex $\mathbf{4}$ are more capable to donate electron while the $\mathrm{C}$ atoms lies on the acetyl pyridine ring favors more acceptance of electron from metallic surface. The presence of more number of heteroatoms in complex 4 than complex 3 gives more preference towards nucleophilic as well as electrophilic attack ${ }^{2}$ and this observation indirectly supports the higher inhibition efficiency of complex 4 than complex 3. So overall the expected prediction of localized attack is quite comparable with the observable results obtained from Fukui indices calculation.

\subsection{Inhibition mechanism}

There are certain physicochemical criteria which dictate the adsorption process of any molecule on the surface like; chemical nature of functional groups involved, the electron density of donor atoms and aromaticity, molecular shape, and size. ${ }^{74,75}$ Any inhibitor molecule may adsorbed on the metal surface via electrostatic type interactions, donor-acceptor interactions, coordinate bonding interaction or combination of all. ${ }^{10,76,77}$ When a particular organic molecule act as a ligand in a metal complex system, in the presence of other co-ligands like azide the tendency for adsorption may increase due to binding through available lone pairs of co-ligand and unused donating sites of ligands. The large size and molecular weight also play a part towards greater inhibitory efficiency. ${ }^{35}$ Taking into consideration these information and $\Delta G_{\text {ads }}^{0}$ values obtained 
from experimental results it can be predictable that adsorption was taken place through physisorption along with chemisorption pathway. Although there is no such huge difference in the $\Delta G_{\text {ads }}^{0}$ values $\left(-27.96 \mathrm{~kJ} \mathrm{~mol}^{-1},-28.35 \mathrm{~kJ} \mathrm{~mol}^{-1}\right.$ and $-28.20 \mathrm{~kJ} \mathrm{~mol}^{-1}$ for complex 3,4 and 5 respectively) between different substances but still from the observed valued it can be presumed that more negative $\Delta G_{\text {ads }}^{0}$ values were obtained with increase of the availability of heteroatoms in case of cooordination polymeric substances (complex 4 and 5). Complex 4 posses most negative $\Delta G_{\text {ads }}^{0}$ value may be due to presence of more number of heteroatom including one non coordinated $\mathrm{O}$ donor atom. Presence of these hetero atoms facilitate both electrostatic as well as coordinate bonding type interactions with the surface. Thus combination of both physisorption along with chemisorption was observed in our systems. Theoretical observation also indicate the overall higher efficiency of polymeric substances and Fukui indices value corelate the active participation of $\mathrm{N}$ aoms of azide towards interaction with mild steel surface.

\section{Conclusions}

The corrosion averting capabilities of the prepared cadmium Schiff base complexes were studied towards mild steel corrosion in $\mathrm{HCl}$ solution. The following outcome can be summarized:

(1) For target-oriented synthesis, firstly Schiff base ligand $\mathbf{L}^{\mathbf{1}}$ [ $N, N$-dimethyl- $N^{\prime}$-(1-pyridin-2-yl-ethylidene)-ethane-1,2-diamine] has been taken as of prime importance where three cadmium complexes have been synthesized. The corrosion inhibition property of cadmium(II) complexes has been scrutinized in step by step manner. Complex 1 where no co-ligand is involved was not found to be significantly active towards corrosion inhibition. Also after employing cyanoacetic acid as a co-ligand in complex 2, no such improvement has been observed in corrosion inhibition property which may be due to its monomeric nature and a lesser number of adsorbing site.

(2) To improve adsorbing site azide ion as a co-ligand has been introduced in complex 3 and structurally adsorbing site has been increased along with the nuclearity of the compound due to bridging nature of the co-ligand. The results are that the azido bridge dimeric complex 3 has shown remarkable corrosion inhibition property towards mild steel.

(3) After discovering the utility of azide ion as co-ligand towards inhibition property we have contemplated to use the other Schiff base ligands $\mathbf{L}^{2}$ [2-morpholino- $N$-(1-(pyridin-2-yl) ethylidene)ethanamine $]$ and $\mathbf{L}^{3} \quad$ [(2-(piperidin-1-yl)- $N-(1-$ (pyridin-2-yl)ethylidene)ethanamine)] to prepare well designed polymeric complex 4 and 5 which have shown very high corrosion inhibition properties due to the presence of increased number of adsorbing sites and this high inhibition efficiency is quite good with respect to the other inorganic systems ${ }^{13,27}$ as well as organic inhibitors. ${ }^{78}$

Thus considering the similar trend of activity among different substances obtained from different experimental as well as theoretical results, it can be concluded that increasing adsorbing sites by increasing nuclearity could be one of the key factors to develop corrosion resistance polymeric metal complexes which are worth for further investigation.

\section{Conflicts of interest}

There are no conflicts to declare.

\section{Acknowledgements}

We thank the Sophisticated Instrument Centre, IIT Indore for the structure elucidation.

\section{References}

1 S. U. Ofoegbu, T. L. P. Galvao, J. R. B. Gomes, J. Tedim, H. I. S. Nogueira, M. G. S. Ferreira and M. L. Zheludkevich, Phys. Chem. Chem. Phys., 2017, 19, 6113-6129.

2 S. K. Saha, A. Dutta, P. Ghosh, D. Sukul and P. Banerjee, Phys. Chem. Chem. Phys., 2016, 18, 17898-17911.

3 O. K. Abiola and A. O. James, Corros. Sci., 2010, 52, 661-664. 4 M. A. Hegazy and I. Aiad, J. Ind. Eng. Chem., 2015, 31, 91-99. 5 A. A. Farag and T. A. Ali, J. Ind. Eng. Chem., 2015, 21, 627-634. 6 I. Ahamad, R. Prasad and M. A. Quraishi, Corros. Sci., 2010, 52, 933-942.

7 S. K. Shanmughan, J. T. Kakkassery, V. P. Raphael and N. Kuriakose, Curr. Chem. Lett., 2015, 4, 67-76.

8 N. K. Gupta, M. A. Quraishi, C. Verma and A. K. Mukherjee, RSC Adv., 2016, 6, 102076-102087.

9 K. R. Ansari, M. A. Quraishi and A. Singh, Corros. Sci., 2014, 79, 5-15.

10 H. Keless, D. M. Emir and M. Keless, Corros. Sci., 2015, 101, 19-31.

11 P. Singh, D. P. Singh, K. Tiwari, M. Mishra, A. K. Singh and V. P. Singh, RSC Adv., 2015, 5, 45217-45230.

12 H. Ashassi-Sorkhabi, B. Shaabani and D. Seifzadeh, Appl. Surf. Sci., 2005, 239, 154-164.

13 P. Singh, A. K. Singh and V. P. Singh, Polyhedron, 2013, 65, 73-81.

14 S. M. A. Hosseini, A. Azimi, I. Sheikhshoaei and M. Salari, J. Iran. Chem. Soc., 2010, 7, 799-806.

15 M. Shabani-Nooshabadi and M. S. Ghandchi, J. Ind. Eng. Chem., 2015, 31, 231-237.

16 S. Bİlgİç and N. Çaliskan, J. Appl. Electrochem., 2001, 31, 7983.

17 M. Ehteshamzade, T. Shahrabi and M. G. Hosseini, Appl. Surf. Sci., 2006, 252, 2949-2959.

18 S. Şafak, B. Duran, A. Yurt and G. Türkoğlu, Corros. Sci., 2012, 54, 251-259.

19 S. Thirugnanaselvi, S. Kuttirani and A. R. Emelda, Trans. Nonferrous Met. Soc. China, 2014, 24, 1969-1977.

20 M. Mishra, K. Tiwari, A. K. Singh and V. P. Singh, Inorg. Chim. Acta, 2015, 425, 36-45.

21 S. A. Soliman, M. S. Metwally, S. R. Selim, M. A. Bedair and M. A. Abbas, J. Ind. Eng. Chem., 2014, 20, 4311-4320.

22 K. R. Ansari and M. A. Quraishi, J. Ind. Eng. Chem., 2014, 20, 2819-2829. 
23 A. Aytaç, Ü. Özmen and M. Kabasakaloğlu, Mater. Chem. Phys., 2005, 89, 176-181.

24 M. A. Hegazy, A. M. Hasan, M. M. Emara, M. F. Bakr and A. H. Youssef, Corros. Sci., 2012, 65, 67-76.

25 Z. Hu, Y. Meng, X. Ma, H. Zhu, J. Li, C. Li and D. Cao, Corros. Sci., 2016, 112, 563-575.

26 N. Yilmaz, A. Fitoz, Ü. Ergun and K. C. Emregül, Corros. Sci., 2016, 111, 110-120.

27 M. Mahdavian and R. Naderi, Corros. Sci., 2011, 53, 11941200.

28 M. Mahdavian and M. M. Attar, Corros. Sci., 2009, 51, 409414.

29 P. Hersch, Nature, 1961, 190, 163-164.

30 S. B. Ade, M. N. Deshpande and D. G. Kolhatkar, J. Chem. Pharm. Res., 2012, 4(2), 1033-1035.

31 A. Aytaç, J. Mater. Sci., 2010, 45, 6812-6818.

32 G. Sheldrick, Acta Crystallogr., Sect. A: Found. Crystallogr., 2008, 64, 112-122.

33 N. S. Gwaram, H. M. Ali, H. Khaledi, M. A. Abdulla, A. H. A. Hadi, T. K. Lin, C. L. Ching and C. L. Ooi, Molecules, 2012, 17, 5952-5971.

34 D.-H. Shi, X.-L. Wang, W.-W. Liu and H. Jin, Synth. React. Inorg., Met.-Org., Nano-Met. Chem., 2012, 42, 480-484.

35 H. M. Abd El-Lateef, Corros. Sci., 2015, 92, 104-117.

36 A. D. Becke, Phys. Rev. A, 1988, 38, 3098-3100.

37 S. Salehzadeh, R. Golbedaghi, I. S. Tidmarsh, N. K. Al-Rasbi, H. Adams and M. D. Ward, Polyhedron, 2008, 27, 3549-3556.

38 S. Kidambi and A. Ramamoorthy, J. Phys. Chem. A, 2002, 106, 10363-10369.

39 M. J. Frisch, G. W. Trucks, H. B. Schlegel, G. E. Scuseria, M. A. Robb, J. R. Cheeseman, G. Scalmani, V. Barone, B. Mennucci, G. A. Petersson, H. Nakatsuji, M. Caricato, X. Li, H. P. Hratchian, A. F. Izmaylov, J. Bloino, G. Zheng, J. L. Sonnenberg, M. Hada, M. Ehara, K. Toyota, R. Fukuda, J. Hasegawa, M. Ishida, T. Nakajima, Y. Honda, O. Kitao, H. Nakai, T. Vreven, J. A. Montgomery Jr., J. E. Peralta, F. Ogliaro, M. J. Bearpark, J. Heyd, E. N. Brothers, K. N. Kudin, V. N. Staroverov, R. Kobayashi, J. Normand, K. Raghavachari, A. P. Rendell, J. C. Burant, S. S. Iyengar, J. Tomasi, M. Cossi, N. Rega, N. J. Millam, M. Klene, J. E. Knox, J. B. Cross, V. Bakken, C. Adamo, J. Jaramillo, R. Gomperts, R. E. Stratmann, O. Yazyev, A. J. Austin, R. Cammi, C. Pomelli, J. W. Ochterski, R. L. Martin, K. Morokuma, V. G. Zakrzewski, G. A. Voth, P. Salvador, J. J. Dannenberg, S. Dapprich, A. D. Daniels, Ö. Farkas, J. B. Foresman, J. V. Ortiz, J. Cioslowski and D. J. Fox, Gaussian 09, Gaussian Inc., Wallingford, CT, USA, 2009.

40 P. Dohare, K. R. Ansari, M. A. Quraishi and I. B. Obot, J. Ind. Eng. Chem., 2017, 52, 197-210.

41 S. H. Rahaman, H. Chowdhury, D. Bose, R. Ghosh, C.-H. Hung and B. K. Ghosh, Polyhedron, 2005, 24, 17551763.

42 S. Sarkar, S. Majumder, S. Sasmal, L. Carrella, E. Rentschler and S. Mohanta, Polyhedron, 2013, 50, 270-282.

43 M. Trivedi, G. Singh, A. Kumar and N. P. Rath, RSC Adv., 2014, 4, 34110-34116.
44 F. A. Afkhami, A. A. Khandar, G. Mahmoudi, W. Maniukiewicz, J. Lipkowski, J. M. White, R. Waterman, S. Garcia-Granda, E. Zangrando, A. Bauza and A. Frontera, CrystEngComm, 2016, 18, 4587-4596.

45 A. Jäntti, M. Wagner, M. Wagner, R. Suontamo, E. Kolehmainen and K. Rissanen, Eur. J. Inorg. Chem., 1998, 1998, 1555-1562.

46 N. A. Odewunmi, S. A. Umoren and Z. M. Gasem, J. Ind. Eng. Chem., 2015, 21, 239-247.

47 M. H. Wahdan, Mater. Chem. Phys., 1997, 49, 135-140.

48 M. M. Solomon, S. A. Umoren and E. J. Abai, J. Mol. Liq., 2015, 212, 340-351.

49 S. Deng, X. Li and H. Fu, Corros. Sci., 2011, 53, 3596-3602. 50 R. Solmaz, Corros. Sci., 2010, 52, 3321-3330.

51 R. Solmaz, G. Kardaş, M. Çulha, B. Yazıcı and M. Erbil, Electrochim. Acta, 2008, 53, 5941-5952.

52 S. V. Lamaka, M. L. Zheludkevich, K. A. Yasakau, R. Serra, S. K. Poznyak and M. G. S. Ferreira, Prog. Org. Coat., 2007, 58, 127-135.

53 M. H. Hussin and M. J. Kassim, Int. J. Electrochem. Sci., 2011, 6, 1396-1414.

54 A. Biswas, S. Pal and G. Udayabhanu, Appl. Surf. Sci., 2015, 353, 173-183.

55 R. Solmaz, Corros. Sci., 2014, 81, 75-84.

56 R. Solmaz, Corros. Sci., 2014, 79, 169-176.

57 K. F. Khaled, K. Babić-Samardžija and N. Hackerman, Corros. Sci., 2006, 48, 3014-3034.

58 M. Mishra, K. Tiwari, P. Mourya, M. M. Singh and V. P. Singh, Polyhedron, 2015, 89, 29-38.

59 C. W. Borgmann, Ind. Eng. Chem., 1937, 29, 814-821.

60 R. G. Pearson, Inorg. Chem., 1988, 27, 734-740.

61 E.-C. Koch, Propellants, Explos., Pyrotech., 2005, 30, 5-16.

62 G. Klopman, J. Am. Chem. Soc., 1968, 90, 223-234.

63 Y. Karzazi, M. E. A. Belghiti, A. Dafali and B. Hammouti, J. Chem. Pharm. Res., 2014, 6, 689-696.

64 S. Kaya, P. Banerjee, S. K. Saha, B. Tuzun and C. Kaya, RSC Adv., 2016, 6, 74550-74559.

65 K. R. Ansari, M. A. Quraishi and A. Singh, J. Ind. Eng. Chem., 2015, 25, 89-98.

66 R. Hasanov, M. Sadıkoğlu and S. Bilgiç, Appl. Surf. Sci., 2007, 253, 3913-3921.

67 T. Koopmans, Physica, 1934, 1, 104-113.

68 I. Lukovits, E. Kálmán and F. Zucchi, Corrosion, 2001, 57, 3-8.

69 L. M. Rodríguez-Valdez, W. Villamisar, M. Casales, J. G. González-Rodriguez, A. Martínez-Villafañe, L. Martinez and D. Glossman-Mitnik, Corros. Sci., 2006, 48, 4053-4064.

70 S. Martinez, Mater. Chem. Phys., 2003, 77, 97-102.

71 X. Li, S. Deng, H. Fu and T. Li, Electrochim. Acta, 2009, 54, 4089-4098.

72 R. G. Pearson, J. Am. Chem. Soc., 1988, 110, 7684-7690.

73 R. R. Contreras, P. Fuentealba, M. Galván and P. Pérez, Chem. Phys. Lett., 1999, 304, 405-413.

74 M. A. Hegazy, M. Abdallah, M. K. Awad and M. Rezk, Corros. Sci., 2014, 81, 54-64. 
75 R. N. Parkins, in Electrochemical Materials Science, ed. J. O. M. Bockris, B. E. Conway, E. Yeager and R. E. White, Springer US, Boston, MA, 1981, pp. 307-331, DOI: $10.1007 /$ 978-1-4757-4825-3_6.

76 A. K. Singh and P. Singh, J. Ind. Eng. Chem., 2015, 21, 552560 .
77 V. S. Sastri, in Green Corrosion Inhibitors, John Wiley \& Sons, Inc., 2011, pp. 139-166, DOI: 10.1002/9781118015438.ch4.

78 N. A. Negm, N. G. Kandile, I. A. Aiad and M. A. Mohammad, Colloids Surf., A, 2011, 391, 224-233. 